\title{
Pathological Complete Response After Immune- Checkpoint Inhibitor Followed by Salvage Surgery for Clinical Stage IV Pulmonary Adenocarcinoma with Continuous Low Neutrophil-to-Lymphocyte Ratio: A Case Report
}

Mitsunori Higuchi ( $\nabla$ higuchi@fmu.ac.jp )

Fukushima Kenritsu Ika Daigaku Aizu Iryo Center

\section{Takahiro Kawamata}

Fukushima Medical University Aizu Medical Center: Fukushima Kenritsu Ika Daigaku Aizu Iryo Center Ikuro Oshibe

Fukushima Medical University Aizu Medical Center: Fukushima Kenritsu Ika Daigaku Aizu Iryo Center Nobutoshi Soeta

Fukushima Medical University Aizu Medical Center: Fukushima Kenritsu Ika Daigaku Aizu Iryo Center

\section{Takuro Saito}

Fukushima Medical University Aizu Medical Center: Fukushima Kenritsu Ika Daigaku Aizu Iryo Center Hiroshi Hojo

Fukushima Medical University Aizu Medical Center: Fukushima Kenritsu Ika Daigaku Aizu Iryo Center Yuki Matsumura

Fukushima Kenritsu Ika Daigaku

Hiroyuki Suzuki

Fukushima Kenritsu lka Daigaku

\section{Case report}

Keywords: non-small cell lung cancer (NSCLC), pathological complete response (CR), immune-checkpoint inhibitor (ICI), salvage surgery, neutrophil-to-lymphocyte ratio (NLR)

Posted Date: December 17th, 2020

DOI: https://doi.org/10.21203/rs.3.rs-127794/v1

License: (c) (i) This work is licensed under a Creative Commons Attribution 4.0 International License.

Read Full License 


\section{Abstract}

Background: Immune-checkpoint inhibitors (ICls) play a crucial role in the treatment of advanced nonsmall cell lung cancer (NSCLC), however, most patients fail this treatment after a limited period. We here report a patient with a pathological complete response (CR) after treatment with ICI for stage IV pulmonary adenocarcinoma.

Case presentation: A 73-year-old man was referred to our hospital because of hoarseness. A roentgenogram and chest CT scan revealed a huge (78-mm diameter) pulmonary tumor in the right upper lobe and a tumor with cavitation in the left lower lobe. A CT scan also showed enlarged upper mediastinal lymph nodes. Transbronchial lung biopsy (TBLB) of the tumors showed adenocarcinomas in both. The tumor in the right upper lobe was considered to be the primary with mediastinal lymph nodes metastasis and that in the left lower lobe a pulmonary metastasis. The disease was determined to be CT4N2M1a stage IVA after whole body evaluation. He was treated with first line chemotherapy comprising cisplatin, pemetrexed, and bevacizumab for six cycles, achieving a partial response. However, 6 months after initial treatment, the primary and metastatic tumors enlarged and he was treated with second line anti-PD-1 therapy for 7 months with a partial response. 18-fluorodeoxyglucose positron emission tomography (FDG-PET) revealed weak accumulation of FDG in the primary tumor only with no accumulation in the left pulmonary metastasis or mediastinal lymph nodes, despite the lymph nodes still being enlarged. He was diagnosed as having ycT1bNOM0 stage IA2 disease and underwent right upper lobectomy. Postoperative pathological findings revealed that cancer tissues had been replaced by scar tissue and that CD4 positive T cells, rather than CD8 positive T cells, were predominant. It was also noted that he had a lower neutrophil-to-lymphocyte ratio (NLR) during immunotherapy than before immunotherapy and after surgery. He was diagnosed to be ypTONOMO stage 0 (Ef.3). His postoperative course was uneventful and he remained well for twelve months after surgery with no further treatment.

Conclusions: Neoadjuvant chemotherapy with ICls for advanced NSCLC may be a promising modality, even for clinical stage IV disease, in the near future. Furthermore, NLR during immunotherapy may be a promising biomarker of ICls treatment.

\section{Background}

Immune-checkpoint inhibitors (ICls) play a crucial role in the treatment of advanced non-small cell lung cancer (NSCLC), however, most patients fail this treatment after a limited period. Previous studies have shown that $20 \%$ of patients who receive ICls achieve a long progression-free survival [1-5]. Radical salvage surgery may be appropriate for patients who achieve down staging after ICls and can result in long-term survival. A recent study on neoadjuvant immunotherapy showed a high major pathological response (MPR) [6] and some case reports have also shown the usefulness of neoadjuvant ICls in patients with advanced NSCLC [7-10]. Herein, we present the case of a 73-year old man with initially unresectable stage IVA adenocarcinoma who subsequently received chemotherapy and ICls followed by resection and achieved a complete pathological response. 


\section{Case Presentation}

A 73-year-old man was referred to our hospital because of hoarseness. A roentgenogram and chest CT scan revealed a huge (78-mm diameter) pulmonary tumor in the right upper lobe and a tumor with cavitation in the left lower lobe (Fig. 1-a, b). A CT scan also showed enlarged upper mediastinal lymph nodes (Fig. 1c). Transbronchial lung biopsy (TBLB) of both tumors showed they were both adenocarcinomas by Hematoxylin-Eosin (H.E.) stain (Fig. 2a, b). The tumor in right upper lobe was considered to be the primary lesion with upper mediastinal lymph nodes metastasis and the left lower lobe was considered to be a pulmonary metastasis. More than $50 \%$ of the cancer tissue in both sides was positive on immunohistochemical staining with anti-PD-L1 antibody (Fig. 2c, d). The disease was determined to be cT4N2M1a stage IVA after whole body evaluation with PET/CT and brain MRI. He was treated with first line chemotherapy comprising cisplatin, pemetrexed, and bevacizumab for six cycles, achieving a partial response (Fig. d-f). However, 6 months later, the primary and metastatic tumors had enlarged and he was treated with second line anti-PD-1 therapy, pembrolizumab, for 7 months, again achieving a partial response. 18-fluorodeoxyglucose positron emission tomography (FDG-PET) revealed weak accumulation of FDG in the primary tumor only, with no accumulation in the left lung metastasis or mediastinal lymph nodes, even though the mediastinal lymph nodes were still enlarged (Fig. 3). He was diagnosed as having ycT1bNOM0 stage IA2 disease and underwent right upper lobectomy. Although he had received preoperative chemotherapy, no intrathoracic adhesions or inflammatory changes were identified with the exception of the mediastinal lymph nodes, which were strongly adherent to the superior vena cava. These nodes were therefore sampled. Postoperative pathological examination of the operative specimens revealed that cancer tissues had been replaced by scar tissue in which CD4 positive T cells, rather than CD8 positive T cells, were predominant (Fig. 4a-c). Additionally, granzyme B was weakly positive (Fig. 4-d). Pathological findings of sampled mediastinal lymph nodes also revealed no viable cancer cells. The pathological diagnosis was ypTONOMO stage 0 (Ef.3). It was also noted the neutrophilto-lymphocyte ratio (NLR) was lower during immunotherapy than before immunotherapy and after surgery (Fig. 5). His postoperative course was uneventful except for grade $1 \mathrm{fever}$ and he has remained well without recurrence, which was identified with FDG-PET and brain MRI, for twelve months since surgery with no additional treatment.

\section{Discussion}

The administration of third generation chemotherapy drugs such as docetaxel, paclitaxel, and gemcitabine has improved the overall survival of advanced patients with NSCLC to 8-10 months [1113]. However, in 2002, Carney concluded that a plateau of efficacy in treating NSCLC had been reached and that no further improvement would be achieved with these conventional chemotherapeutic drugs [14]. From 2000, targeted therapy such as epidermal growth factor receptor-tyrosine kinase inhibitor (EGFR-TKI), anaplastic lymphoma kinase- tyrosine kinase inhibitor (ALK-TKI), ROS1-TKI, and v-raf murine sarcoma viral oncogene homolog B1 (BRAF)/(mitogen-activated protein kinase (MEK) inhibitors have been used to treat NSCLC and found to be extremely effective. These targeted therapies administered as 
neoadjuvant treatment have been shown to be capable of converting advanced NSCLC to an operable status $[15,16]$. Furthermore, ICls such as nivolumab, pembrolizumab, durvalumab, and atezolizumab have also been shown to achieve long-term survival in some patients with advanced NSCLC [1-5].

A randomized phase III study with preoperative cisplatin and gemcitabine achieved better survival of patients with stage IIB to IIIA NSCLC than did surgery alone [17]. Additionally, a meta-analysis of neoadjuvant chemotherapy for clinical stage I-IIIA NSCLC showed that preoperative chemotherapy achieves significantly better overall survival, time to distant recurrence, and recurrence-free survival than does surgery alone in patients with resectable NSCLC [18]. Although these reports encourage the thoracic surgeon to administer neoadjuvant chemotherapy to patients with clinical stage IIIA NSCLC, the quality and quantity of evidence concerning preoperative neoadjuvant chemotherapy is inferior to that available for postoperative adjuvant chemotherapy, such as that provided by the International Adjuvant Lung Cancer (IALT), JBR.10, and Adjuvant Navelbine International Trialist Association (ANITA) trials [19-21]. Therefore, neoadjuvant chemotherapy has not been strongly recommended for advanced NSCLC to date.

Antibodies that block programed death 1 (PD-1) and programmed death ligand 1 (PD-L1) protein improve survival in patients with advanced NSCLC [1-5]. Recently, PD-1 blockade and neoadjuvant nivolumab have been shown to induce MPRs in $45 \%$ of tumors resected from patients with resectable clinical stage I to IIIA NSCLC [6], MPR being defined as tumors with no more than $10 \%$ viable tumor cells. Provencio et al. reported at the 2018 World Conference on Lung Cancer (19th WCLC; Toronto, Canada; abstract \#OA01.05) that MPR was achieved in $64 \%$ of resected tumors by combination therapy comprising atezolizumab, carboplatin, and nab-paclitaxel. Additionally, Shu et al. reported at the 2018 American Society of Clinical Oncology Annual Meeting (Chicago, IL, USA; abstract \#8532) that MPR was achieved in $80 \%$ of resected tumors with combination therapy comprising nivolumab, carboplatin, and paclitaxel. Combination therapy with $\mathrm{ICl}$ and platinum-based chemotherapy is currently considered to be a promising combination for treating advanced NSCLC $[22,23]$. The increasing use of ICls in the treatment of advanced NSCLC makes it important for surgeons to understand the potential indications for resection. Some recent studies reported that immunotherapy had achieved sufficient down-staging in eight patients with clinical stage III or IV NSCLC to enable salvage surgery [7-10] (Table 1). Amazingly, six of nine cases (these eight plus the present patient) were proven to have pathological Ef.3 disease. These findings indicate that neoadjuvant immunotherapy with or without cytotoxic chemotherapy could be administered as novel preoperative therapy in the near future, even in patients with clinical stage IV NSCLC. At this point, the indications for surgery for patients with stage IV NSCLC initially who achieve down-staging after chemotherapy or chemoradiotherapy have not been clearly established. Our patient had maintained a partial response for 7 months after initial treatment with pembrolizumab. We therefore decided to perform salvage surgery after discussions with other physicians and obtaining informed consent to surgery from the patient and his family members. In this new era of chemotherapy, it is important to assess in a timely manner which patients in this category is have indications for surgery.

Another serious issue that needs to be resolved is the lack of reliable biomarkers for predicting the effect and prognosis of immunotherapy. Currently, there are several promising biomarkers, including PD-L1 
expression, tumor mutation burden (TMB) and gene expression signatures [24]. However, these factors are not reliable. After reviewing the clinical value of the NLR in patients with NSCLC treated with ICls, Jiang et al. set an NLR cutoff value of 5 and concluded that a high blood NLR (more than 5 ) is associated with shorter progression-free survival and overall survival in patients treated with ICls; they therefore suggested that the NLR has potential predictive and prognostic value [25]. In our patient, the NLR was less than 3 before immunotherapy and was persistently 1 to 2 during immunotherapy, increasing after surgery. To the best of our knowledge, this is the first detailing changes in NLR throughout multidisciplinary treatment. In our patient, postoperative pathological examination revealed that CD4 positive $T$ lymphocytes predominated over CD8 positive $T$ lymphocytes. CD4 positive lymphocytes include effector $T$ cells and regulatory $T$ cells and the latter induce immunological tolerance. This proportion of T lymphocytes in the resected specimen is extremely interesting. When viable cancer cells are present, CD8 positive lymphocytes are the predominant tumor infiltration lymphocytes (TILs) that fight cancer cells. However, if the cancer cells are eliminated totally and only scar tissue remains, both CD8 and granzyme B-positive lymphocytes are not necessary and regulatory $T$ cells would gather to regulate attacks on non-cancer tissues and create a new environment in the scar tissues. In our patient, granzyme B was weakly positive, which suggests that the cytotoxic abilities of T cells had already decreased. When immunotherapy achieves MPR or CR in patients with advanced NSCLC, the NLR would remain low during immunotherapy, CD4-positive lymphocytes would accumulate and cytotoxic CD8positive T cells would disappear around the tumor/scar tissue to maintain immunological tolerance, as occurred in our patient.

The present findings indicate that pulmonary resection after $\mathrm{ICl}$ treatment is feasible and may be free of major complications. However, the optimal duration of ICI therapy and the best predictive biomarkers of response are still unknown. Clinical trials are needed to define the best criteria for duration of preoperative $\mathrm{ICl}$ therapy and timing of proceeding with resection in patients with advanced NSCLC, including clinical stage IV, receiving neoadjuvant ICI treatment.

\section{Conclusions}

ICls are effective treatment for advanced NSCLC and can achieve CR. This case report shows that the use of ICls in a neoadjuvant setting can enable surgical resection of tumors that were initially considered inoperable. Neoadjuvant chemotherapy with ICls for advanced NSCLC will likely become a promising modality, even for clinical stage IV disease, in the near future. Furthermore, NLR during immunotherapy may be a promising biomarker for predicting the efficacy of ICI treatment.

\section{Abbreviations}

ADC

adenocarcinoma

ALK

anaplastic lymphoma kinase 
BEV

bevacizumab

BRAF

v-raf murine sarcoma viral oncogene homolog B1

CBDCA

carboplatin

CD4

cluster of differentiation 4

CD8

cluster of differentiation 8

$\mathrm{CR}$

complete response

CTLA-4

cytotoxic T-lymphocyte associated antigen 4

DFS

disease-free survival

EGFR-TKI

epidermal growth factor receptor-tyrosine kinase inhibitor

FDG-PET

18-fluorodeoxyglucose positron emission tomography

H.E.

hematoxylin-eosin stain

ICls

immune-checkpoint inhibitors

LCNEC

large-cell neuroendocrine carcinoma

LUL

left upper lobectomy

MPR

major pathological response

NLR

neutrophil-to-lymphocyte ratio

NOS

not otherwise specified

NSCLC

non-small cell lung cancer

PD-1

programmed death 1

PD-L1

programed death ligand 1 
PEM

pemetrexed

ROS-1

c-ros-1

RLL

right lower lobectomy

RUL

right upper lobectomy

SQ

squamous cell carcinoma

TBLB

transbronchial lung biopsy

TIL

tumor infiltrating lymphocyte

TMB

tumor mutation burden

TPS

tumor proportion score

VP-16

etoposide

\section{Declarations}

Ethics approval and consent to participate: It was not necessary to obtain ethical approval for this case report; however, written consent was obtained from the patient for the publication of this case report and accompanying images.

Consent for publication: Written consent was obtained from the patient for the publication of this case report and accompanying images.

Availability of data and materials: Data will not be shared because this is a case report and the privacy of this participant should be protected.

Competing Interests: The authors declare that they have no competing interests.

Funding: None.

Authors' contributions: $\mathrm{MH}$ collected and assembled the data and drafted the article. TK, KM, IO, NS, TS, $\mathrm{HH}$ and YM helped to collect the data. HS helped to draft the article and finally approved the article. All authors have read and approved the final manuscript.

Acknowledgements: The authors thank Mr. Takashi Sato, Ms. Miho Sagawa, and Ms. Michie Kojimahara from the Department of Pathology, Aizu Medical Center, Fukushima Medical University for their excellent 
technical work and support and Dr. Trish Reynolds, MBBS, FRACP, from Edanz Group

(www.edanzediting.com/ac) for editing a draft of this manuscript.

\section{Author's information:}

Department of Thoracic Surgery, Aizu Medical Center, Fukushima Medical University, 21-2-Maeda, Tanisawa, Kawahigashi, Aizuwakamatsu 969-3492, Japan

\section{References}

1. Bahmer J, Reckamp KL, Baas P, Crino L, Eberhardt WE, Poddubskaya E, et al. Nivolumab versus docetaxel in advanced squamous-cell non-small-cell lung cancer. N Engl J Med. 2015;373:123-35.

2. Borghaei H, Paz-Ares L, Horn L, Spigel DR, Steins M, Ready NE, et al. Nivolumab versus docetaxel in advanced nonsquamous non-small-cell lung cancer. N Engl J Med. 2015;373:1627-39.

3. Reck M, Rodríguez-Abreu D, Robinson AG, Hui R, Croszi T, Fülöp A, et al. Pembrolizumab versus chemotherapy for PD-L1-positive non-small-cell lung cancer. N Engl J Med. 2016;375:1823-33.

4. Antonia SJ, Villegas A, Daniel D, Vicente D, Murakami S, Hui R, et al. Durvalumab after chemoradiotherapy in stage III non-small-cell lung cancer. N Engl J Med. 2017;377:1919-29.

5. Rittmeyer A, Barlesi F, Waterkamp D, Park K, Ciardiello F, Pawel JV, et al. Atezolizumab versus docetaxel in patients with previously treated non-small-cell lung cancer (OAK): a phase 3, open-label, multicenter randomized controlled trial. Lancet. 2017;389:255-65.

6. Forde PM, Chaft JE, Smith KN, Anagnostou V, Cottrell TR, Hellmann MD, et al. Neoadjuvant PD-1 blockade in resectable lung cancer. N Engl J Med. 2018;378:1976-86.

7. Hill A, Gong J, Wilczynski S, Mirza R, Erhunmwunsee L, Salgia R. Complete pathologic response when adding pembrolizumab to neoadjuvant chemotherapy in stage IIIA non-small-cell lung cancer. J Oncol Pract. 2018;14:569-71.

8. Chaft JE, Hellmann MD, Velez MJ, Travis WD, Rusch VW. Initial experience with lung cancer resection following treatment with T cell checkpoint inhibitor therapy. Ann Thorac Surg. 2017;104:e217-8.

9. Mauclet C, Duplaquet F, Pirard L, Rondelet B, Dupont M, Pop-Stanciu C, et al. Complete tumor response of a locally advanced lung large-cell neuroendocrine carcinoma after palliative thoracic radiotherapy and immunotherapy with nivolumab. Lung Cancer. 2019;128:53-6.

10. Tang Y, Li Y, Zhang L, Tong G, Ou Z, Wang Z, et al. Pathologic complete response to preoperative immunotherapy in a lung adenocarcinoma patient with bone metastasis: A case report. Thoracic Cancer. 2020;11:1094-8.

11. Schiller JH, Harrington D, Belani CP, Langer C, Sandler A, Krook J, et al. Comparison of four chemotherapy regimens for advanced non-small-cell lung cancer. N Engl J Med. 2002;346:92-8.

12. Azzoli CG, Temin S, Aliff T, Baker S Jr, Brahmer J, Johnson DH, et al. Focused update of 2009 American Society of Clinical Oncology clinical practice guideline update on chemotherapy for stage IV non-small-cell lung cancer. J Clin Oncol. 2011;29:3825-31. 
13. Peters S, Adjei AA, Gridelli C, Reck M, Kerr K, Felip E, et al. Metastatic non-small-cell lung cancer (NSCLC): ESMO Clinical Practice Guidelines for diagnosis, treatment and follow-up. Ann Oncol. 2012;23(Suppl 7):vii56-64.

14. Carney DN. Lung cancer-time to move on from chemotherapy. N Engl J Med. 2002;346:126-8.

15. Wang Q, Wang H, Li P, Zhu H, He C, Wei B, et al. Erlotinib-based perioperative adjuvant therapy for a case of unresectable stage IIIA (N2) nonsmall cell lung cancer. Am J Med Sci. 2010;340:321-5.

16. Shen H, Zhong X, Ge XQ, Huang JJ, Yuan Y. Surgical resection of lung adenocarcinoma without EGFR mutation after neoadjuvant gefitinib treatment. Clin Respir J. 2010;4:192-3.

17. Scagliotti GV, Pastorino U, Vansteenkiste JF, Spaggiari L, Facciolo F, Orlowski TM, et al. Randomized phase III study of surgery alone or surgery plus preoperative cisplatin and gemcitabine in stage IB to IIIA non-small-cell lung cancer. J Clin Oncol. 2012;30:172-8.

18. NSCLC Meta-analysis Collaborative Group. Preoperative chemotherapy for non-small-cell lung cancer: a systemic review and meta-analysis of individual participant data. Lancet. 2014;383:156171.

19. Arriagada R, Bergman B, Dunant A, Chevalier T, Pignon JP, Vansteenkiste J. Cisplatin-based adjuvant chemotherapy in patients with completely resected non-small-cell lung cancer. $\mathrm{N}$ Engl $\mathrm{J}$ Med. 2004;350:351-9.

20. Winton T, Livingston R, Johnson D, Rigas J, Johnston M, Butts C, et al. Vinorelbine plus cisplatin vs. observation in resected non-small-cell lung cancer. N Engl J Med. 2005;352:2589-97.

21. Douillard JY, Rosell R, Lena MD, Carpagnano F, Ramlau R, Gonzales JL, et al. Adjuvant vinorelbine plus cisplatin versus observation in patients with completely resected stage IB-IIIA non-small-cell lung cancer (Adjuvant Navelbine International Trialist Association [ANITA]): a randomized controlled trial. Lancet Oncol. 2006;7:719-27.

22. Gandhi L, Rodriguez-Abreu D, Gadgeel S, Esteban E, Felip E, Angelis FD, et al. Pembrolizumab plus chemotherapy in metastatic non-small-cell lung cancer. N Engl J Med. 2018;378:2078-92.

23. Socinsky MA, Jotte RM, Cappuzzo F, Orlandi F, Stroyakovsky D, Nogami N, et al. Atezolizumab for first-line treatment of metastatic nonsquamous NSCLC. N Engl J Med. 2018;378:2288-301.

24. Tray N, Weber JS, Adams S. Predictive biomarkers for checkpoint immunotherapy: current status and challenges for clinical application. Cancer Immunol Res. 2018;6:1122-8.

25. Jiang T, Bai Y, Zhou F, Li W, Gao G, Su C, et al. Clinical value of neutron-to-lymphocyte ratio in patients with non-small-cell lung cancer treated with PD-1/PD-L1 inhibitors. Lung Cancer. 2019;130:76-83.

\section{Tables}

Due to technical limitations, table 1 is only available as a download in the Supplemental Files section.

\section{Figures}




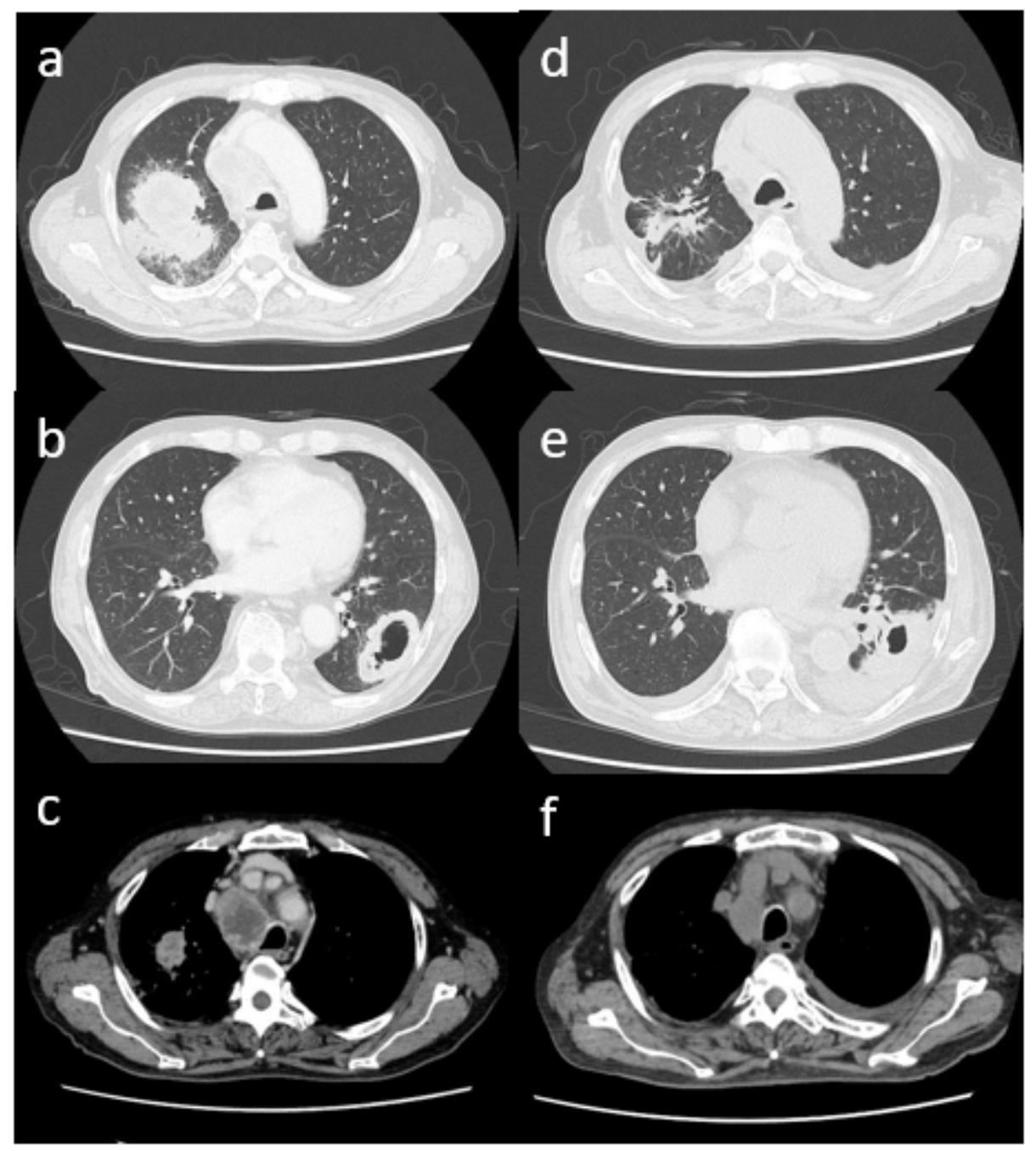

Figure 1

CT scan image showing a huge (78-mm diameter) pulmonary tumor in the right upper lobe (a) and a tumor with cavitation in the left lower lobe (b). CT scan image showing enlarged upper mediastinal lymph nodes (LNs) (c). After six cycles of 1st line chemotherapy, the the size of primary tumor was decreased (d) and the metastatic tumor (e) had enlarged with pleural effusion and mediastinal LNs were also enlarged ( $f)$. 


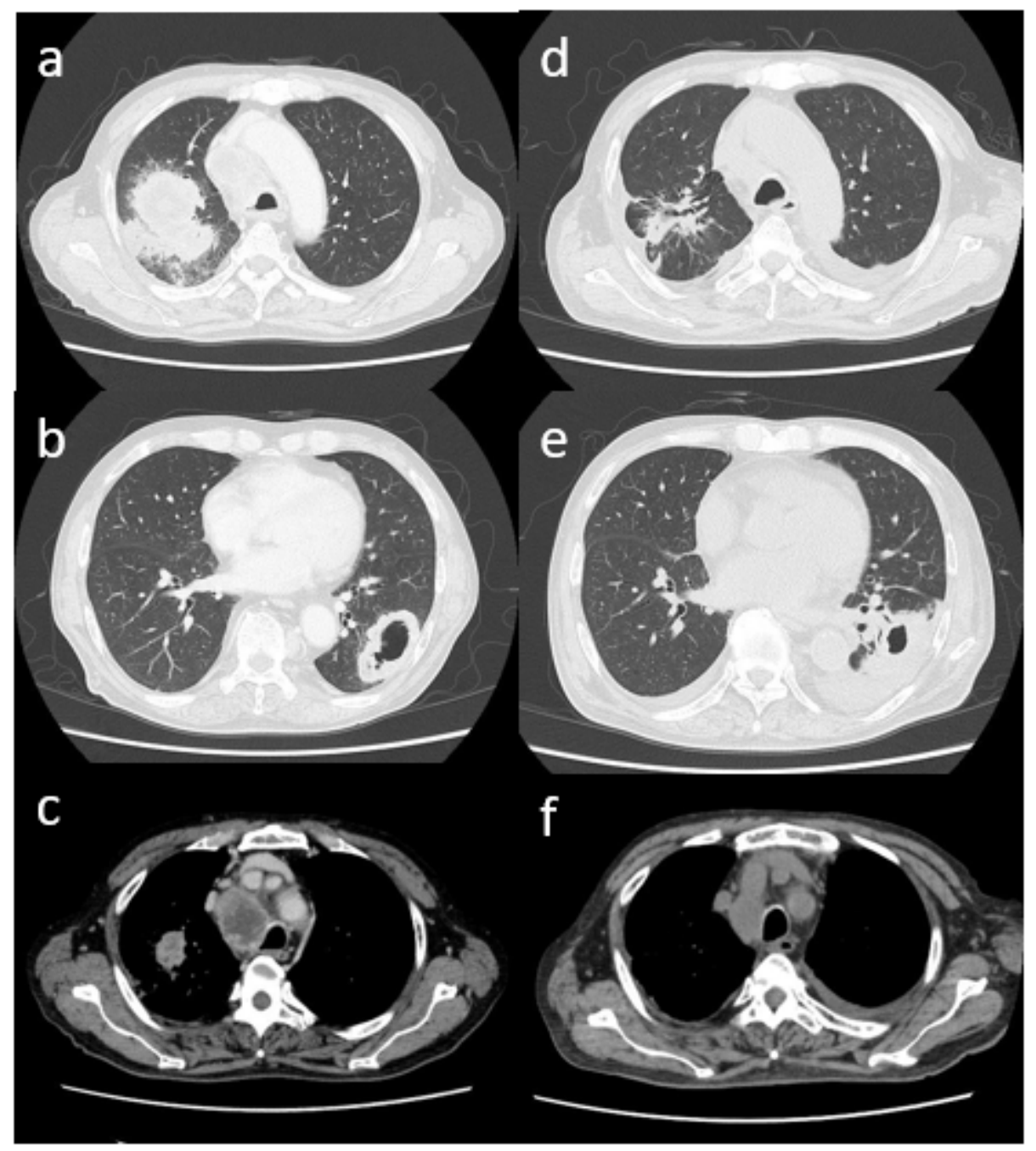

Figure 1

CT scan image showing a huge (78-mm diameter) pulmonary tumor in the right upper lobe (a) and a tumor with cavitation in the left lower lobe (b). CT scan image showing enlarged upper mediastinal lymph nodes (LNs) (c). After six cycles of 1st line chemotherapy, the the size of primary tumor was decreased (d) and the metastatic tumor (e) had enlarged with pleural effusion and mediastinal LNs were also enlarged ( $f)$. 


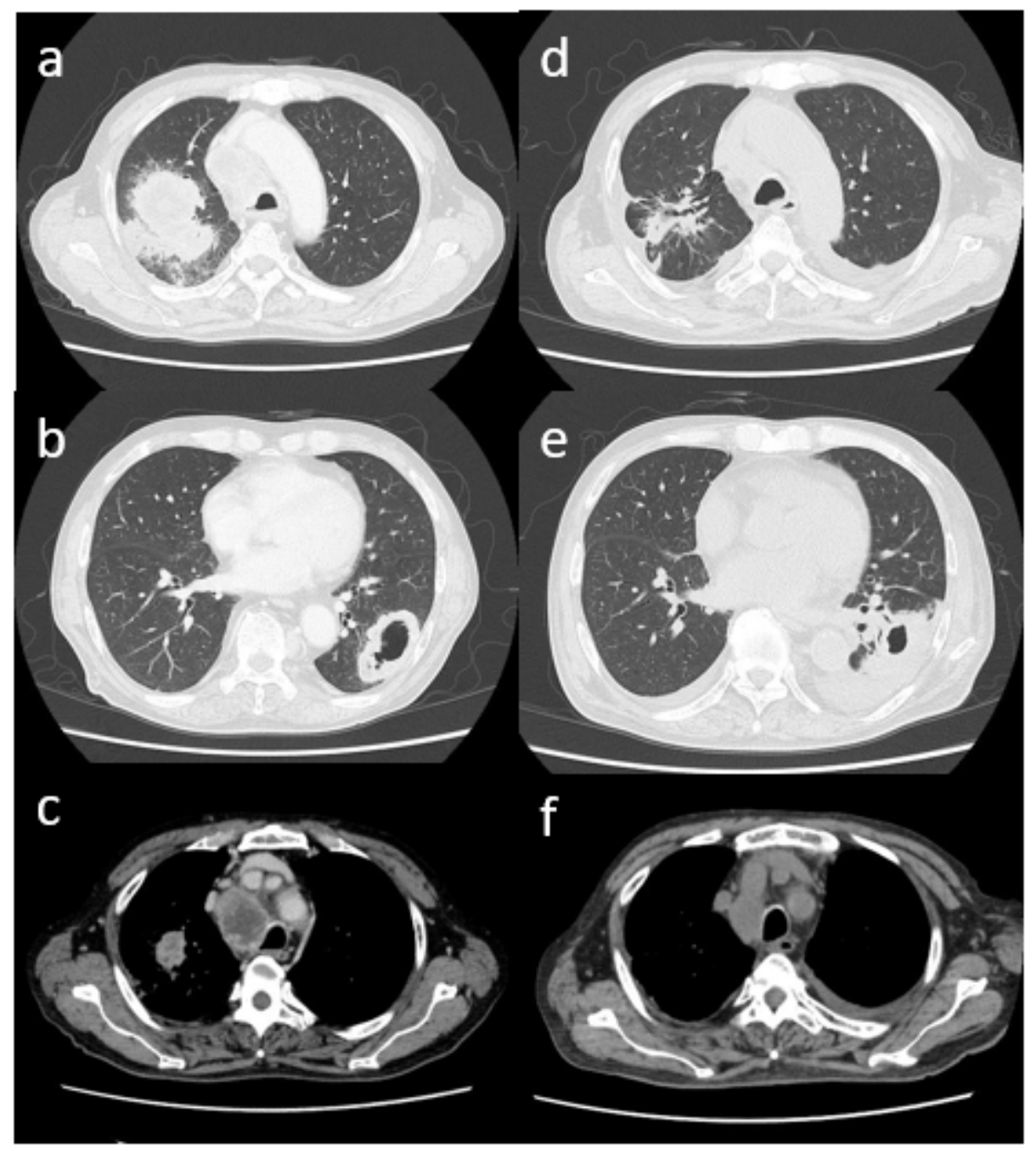

Figure 1

CT scan image showing a huge (78-mm diameter) pulmonary tumor in the right upper lobe (a) and a tumor with cavitation in the left lower lobe (b). CT scan image showing enlarged upper mediastinal lymph nodes (LNs) (c). After six cycles of 1st line chemotherapy, the the size of primary tumor was decreased (d) and the metastatic tumor (e) had enlarged with pleural effusion and mediastinal LNs were also enlarged ( $f)$. 


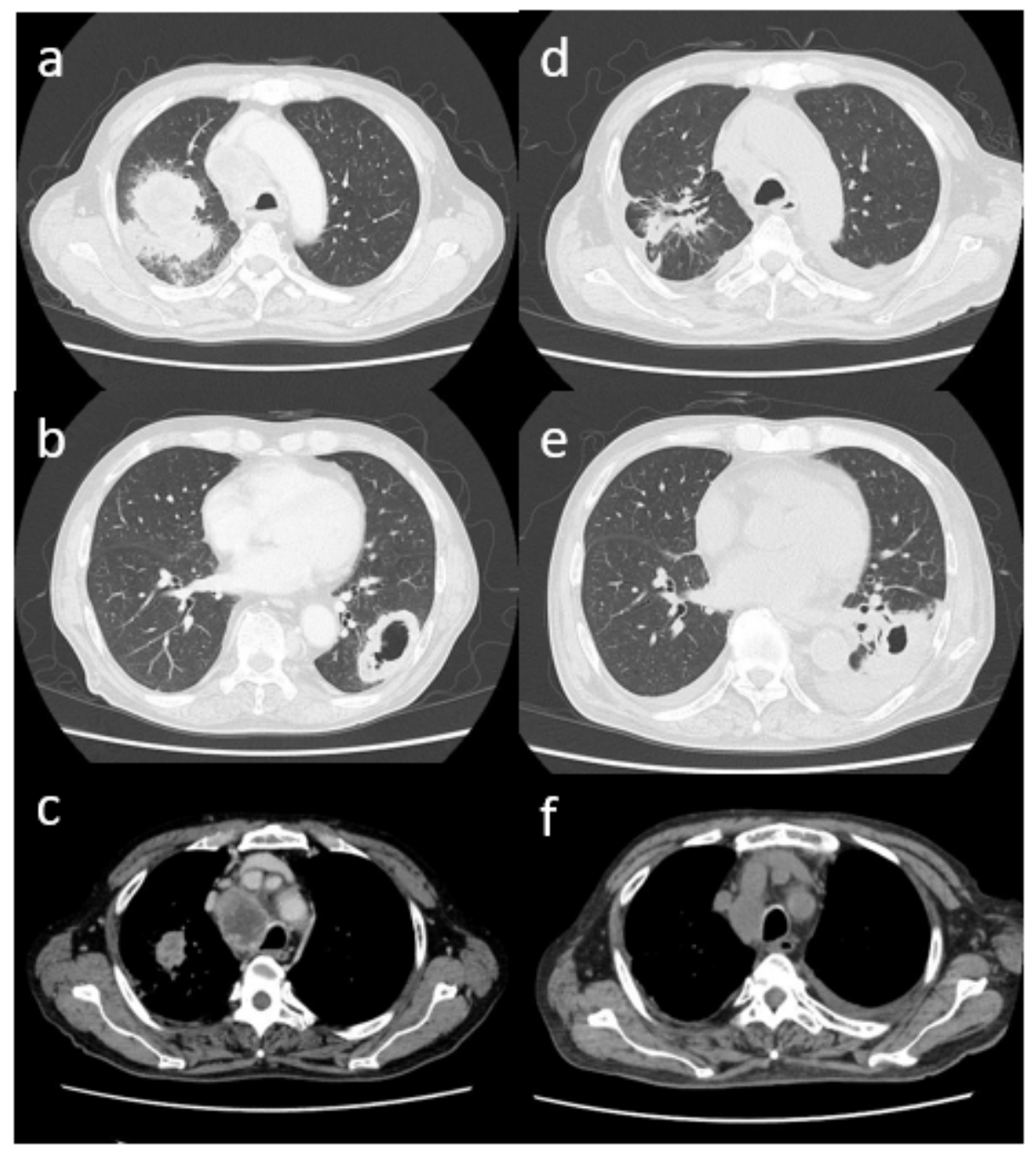

Figure 1

CT scan image showing a huge (78-mm diameter) pulmonary tumor in the right upper lobe (a) and a tumor with cavitation in the left lower lobe (b). CT scan image showing enlarged upper mediastinal lymph nodes (LNs) (c). After six cycles of 1st line chemotherapy, the the size of primary tumor was decreased (d) and the metastatic tumor (e) had enlarged with pleural effusion and mediastinal LNs were also enlarged ( $f)$. 


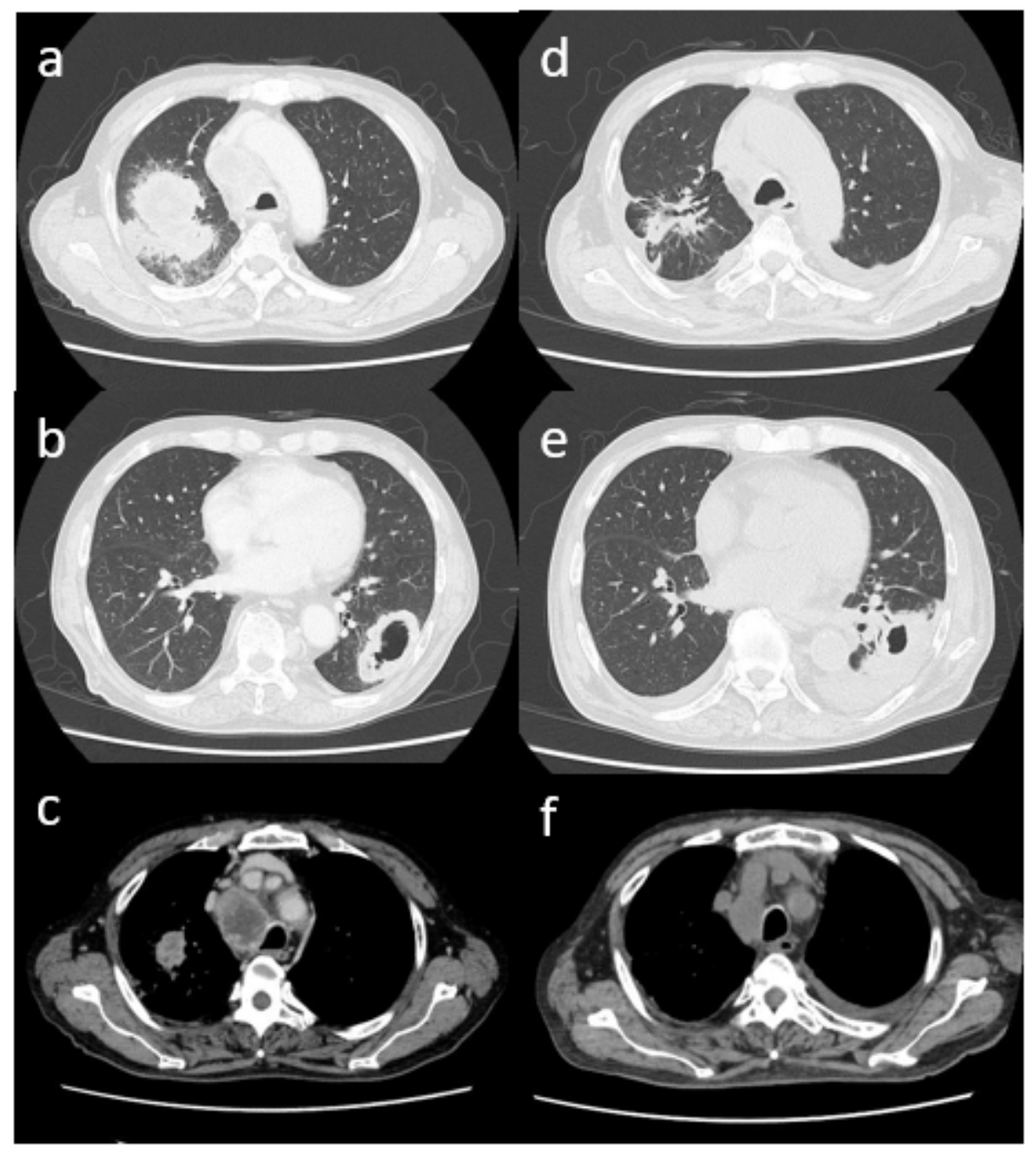

Figure 1

CT scan image showing a huge (78-mm diameter) pulmonary tumor in the right upper lobe (a) and a tumor with cavitation in the left lower lobe (b). CT scan image showing enlarged upper mediastinal lymph nodes (LNs) (c). After six cycles of 1st line chemotherapy, the the size of primary tumor was decreased (d) and the metastatic tumor (e) had enlarged with pleural effusion and mediastinal LNs were also enlarged ( $f)$. 


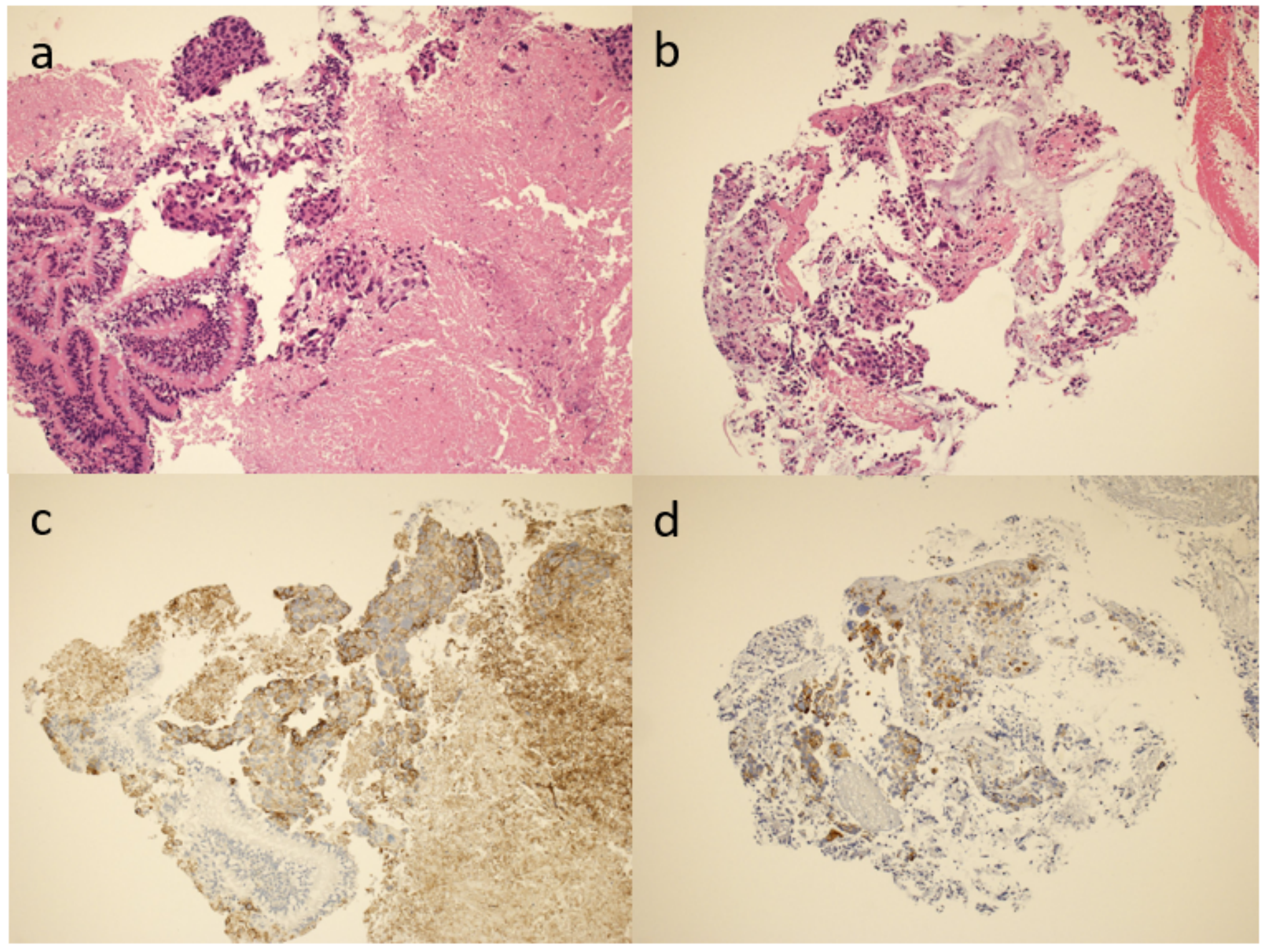

Figure 2

Photomicrographs of transbronchial lung biopsy (TBLB) specimens from both lung tumors showing both are adenocarcinomas (H. E. ×100) (right side: a, left side: b). Photomicrographs of immunohistochemical staining for anti-PD-L1 antibody showing positivity in both tumors (anti-PD-1 antibody $\times 100$ ) (right side: C, left side: $d)$. 


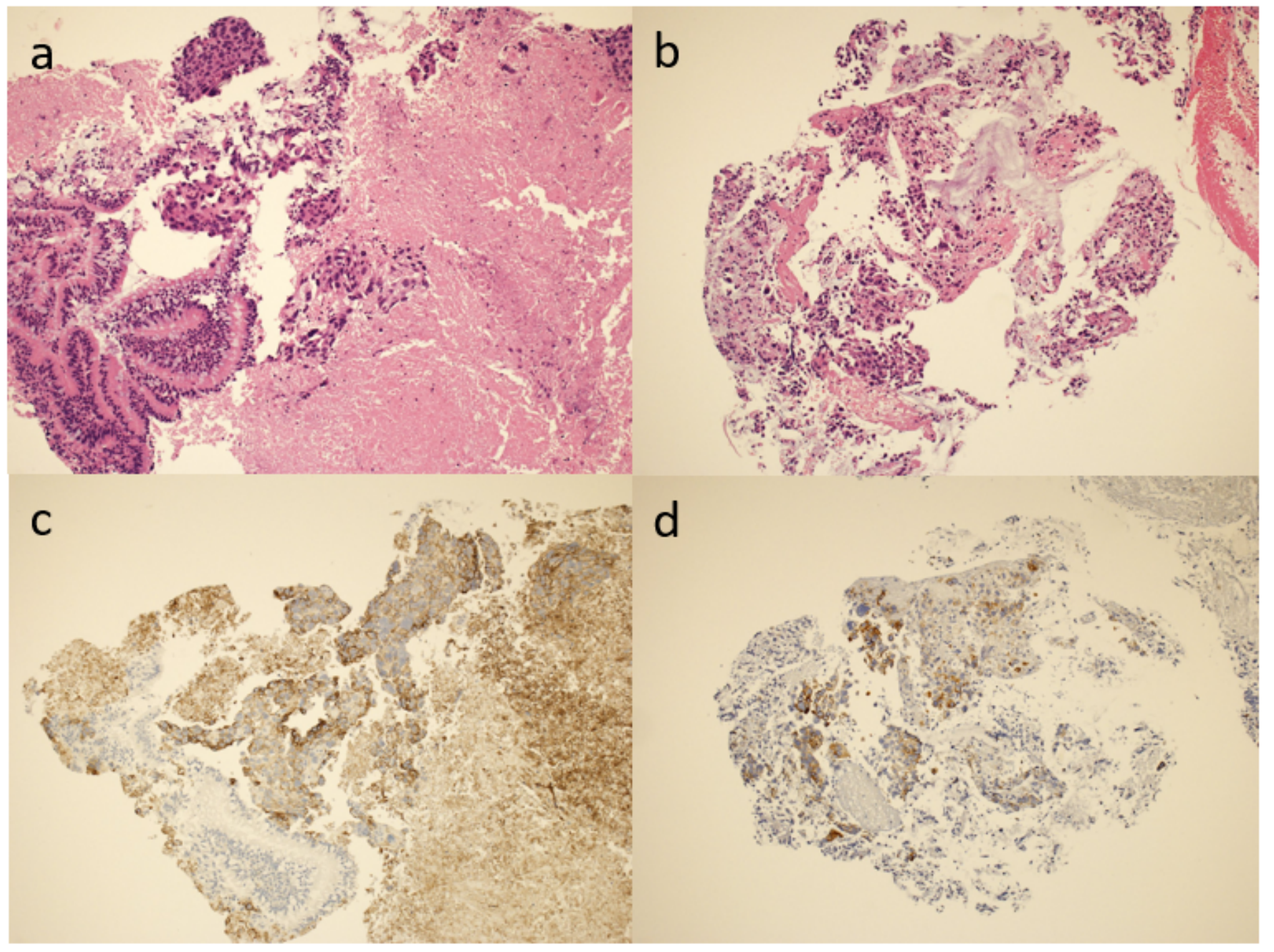

Figure 2

Photomicrographs of transbronchial lung biopsy (TBLB) specimens from both lung tumors showing both are adenocarcinomas (H. E. ×100) (right side: a, left side: b). Photomicrographs of immunohistochemical staining for anti-PD-L1 antibody showing positivity in both tumors (anti-PD-1 antibody $\times 100$ ) (right side: C, left side: $d)$. 


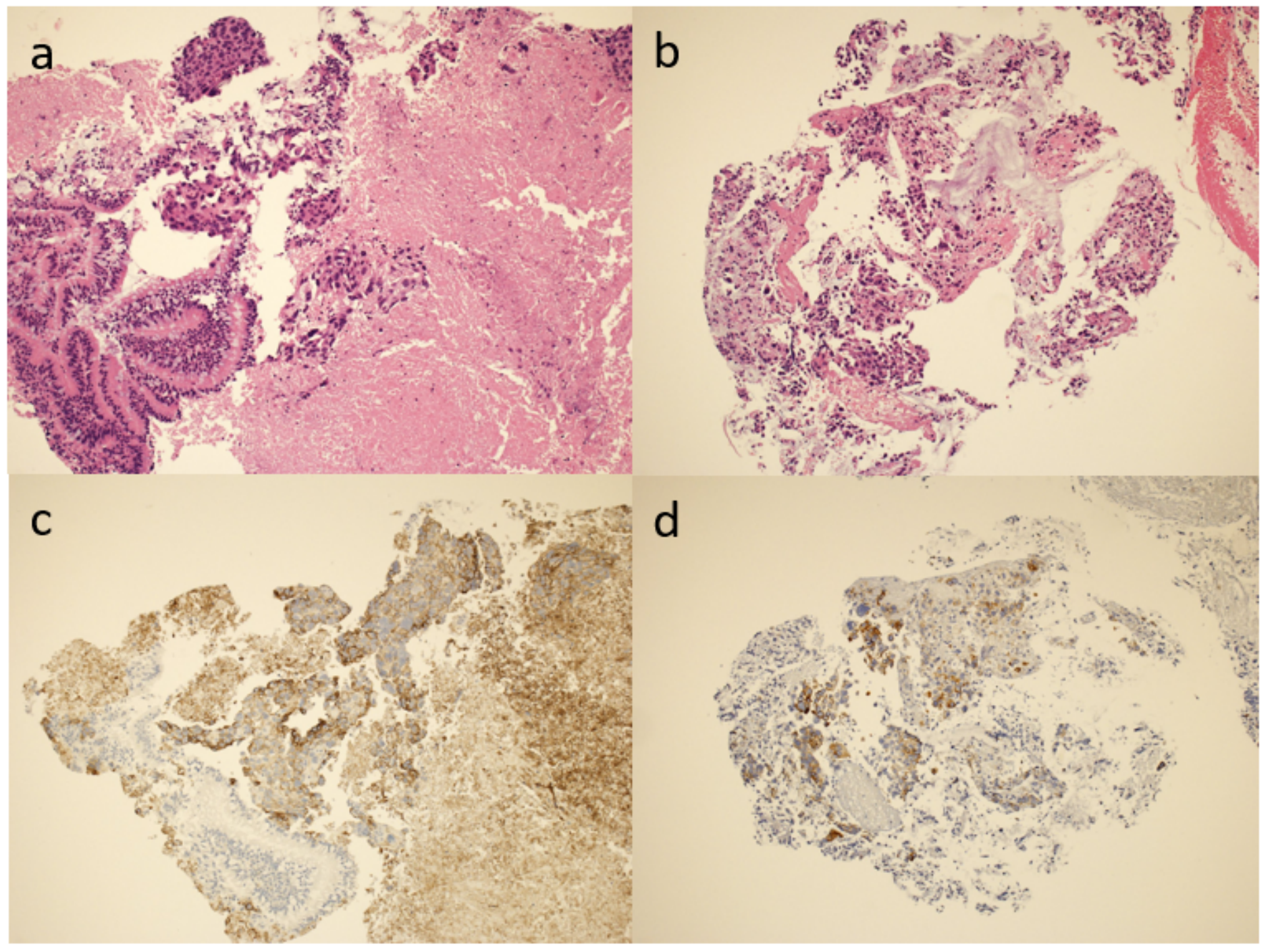

Figure 2

Photomicrographs of transbronchial lung biopsy (TBLB) specimens from both lung tumors showing both are adenocarcinomas (H. E. ×100) (right side: a, left side: b). Photomicrographs of immunohistochemical staining for anti-PD-L1 antibody showing positivity in both tumors (anti-PD-1 antibody $\times 100$ ) (right side: C, left side: $d)$. 


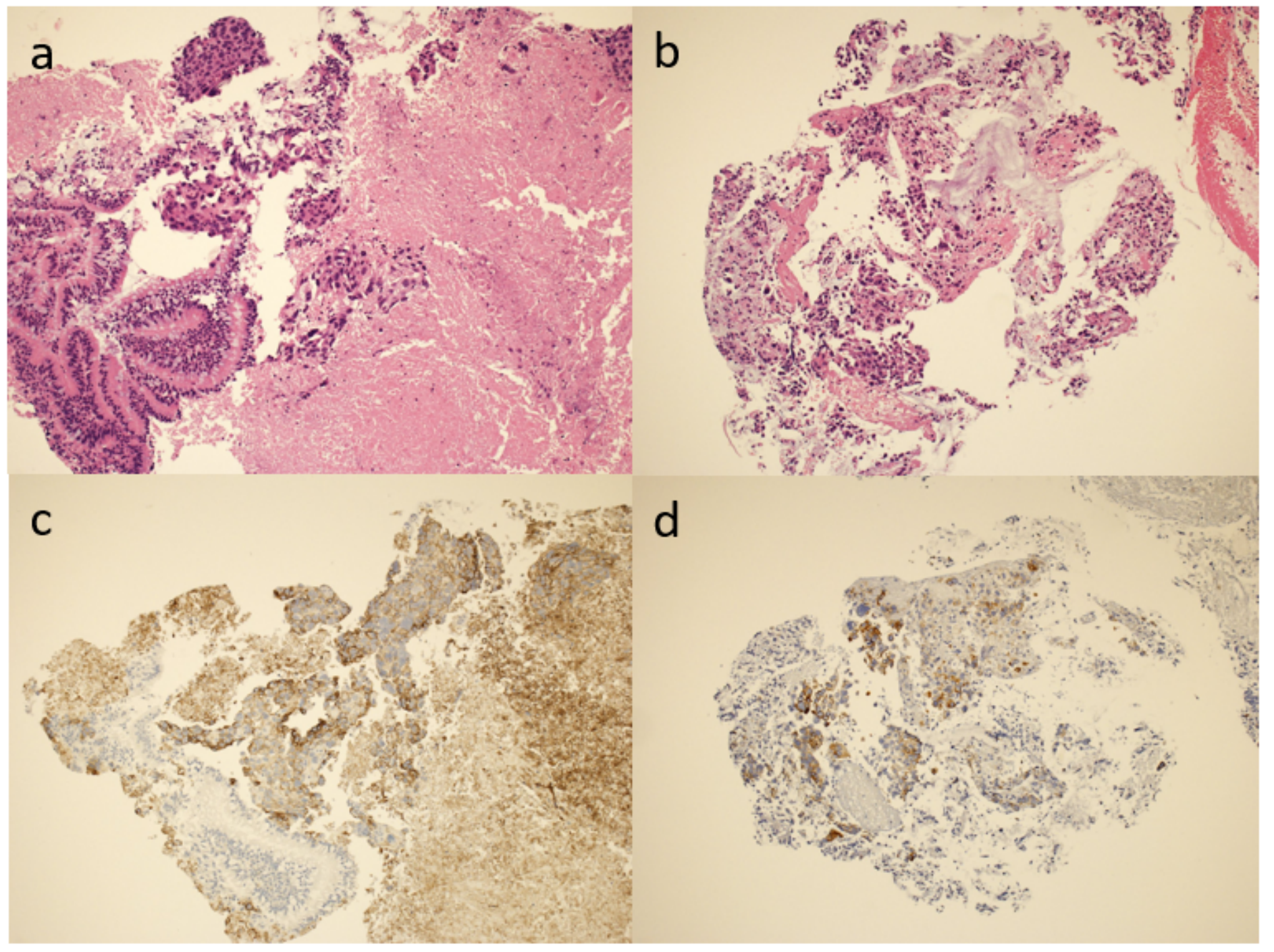

Figure 2

Photomicrographs of transbronchial lung biopsy (TBLB) specimens from both lung tumors showing both are adenocarcinomas (H. E. ×100) (right side: a, left side: b). Photomicrographs of immunohistochemical staining for anti-PD-L1 antibody showing positivity in both tumors (anti-PD-1 antibody $\times 100$ ) (right side: C, left side: $d)$. 


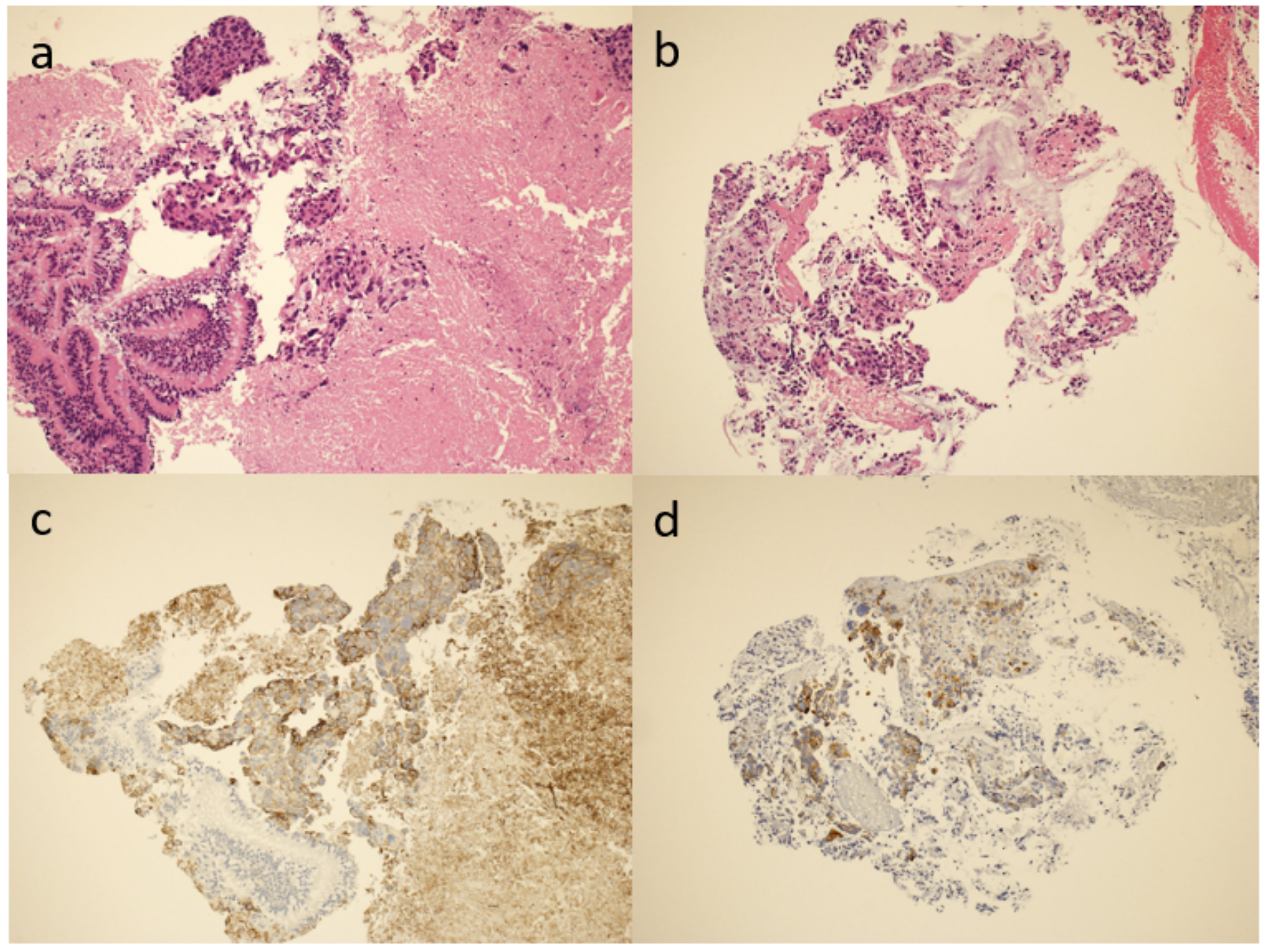

Figure 2

Photomicrographs of transbronchial lung biopsy (TBLB) specimens from both lung tumors showing both are adenocarcinomas (H. E. ×100) (right side: a, left side: b). Photomicrographs of immunohistochemical staining for anti-PD-L1 antibody showing positivity in both tumors (anti-PD-1 antibody $\times 100$ ) (right side: C, left side: $d)$. 


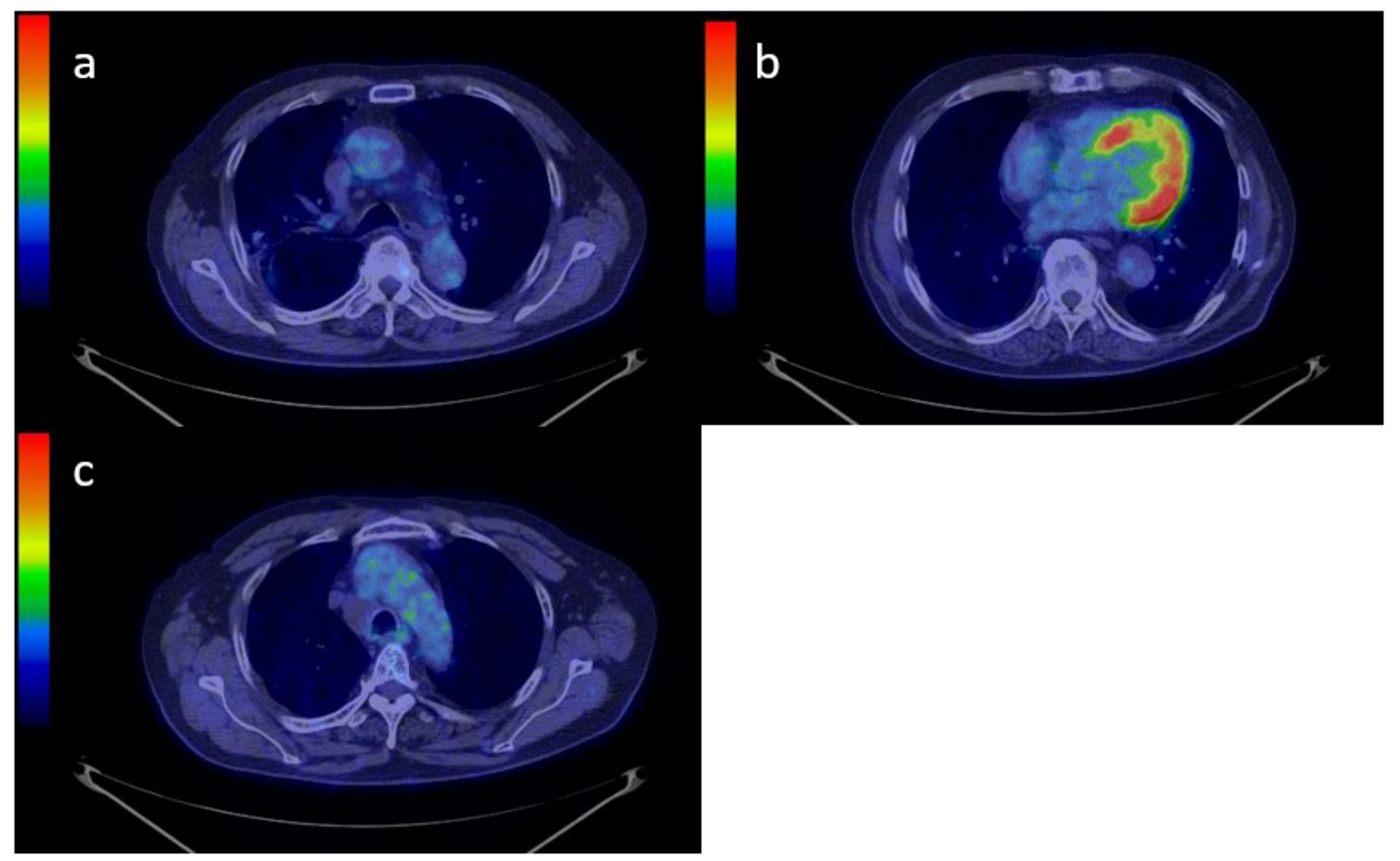

\section{Figure 3}

FDG-PET images showing weak accumulation of FDG in the primary tumor (a) but no accumulation on the left metastatic tumor (b) or mediastinal lymph nodes (c), even though the latter are still enlarged. 


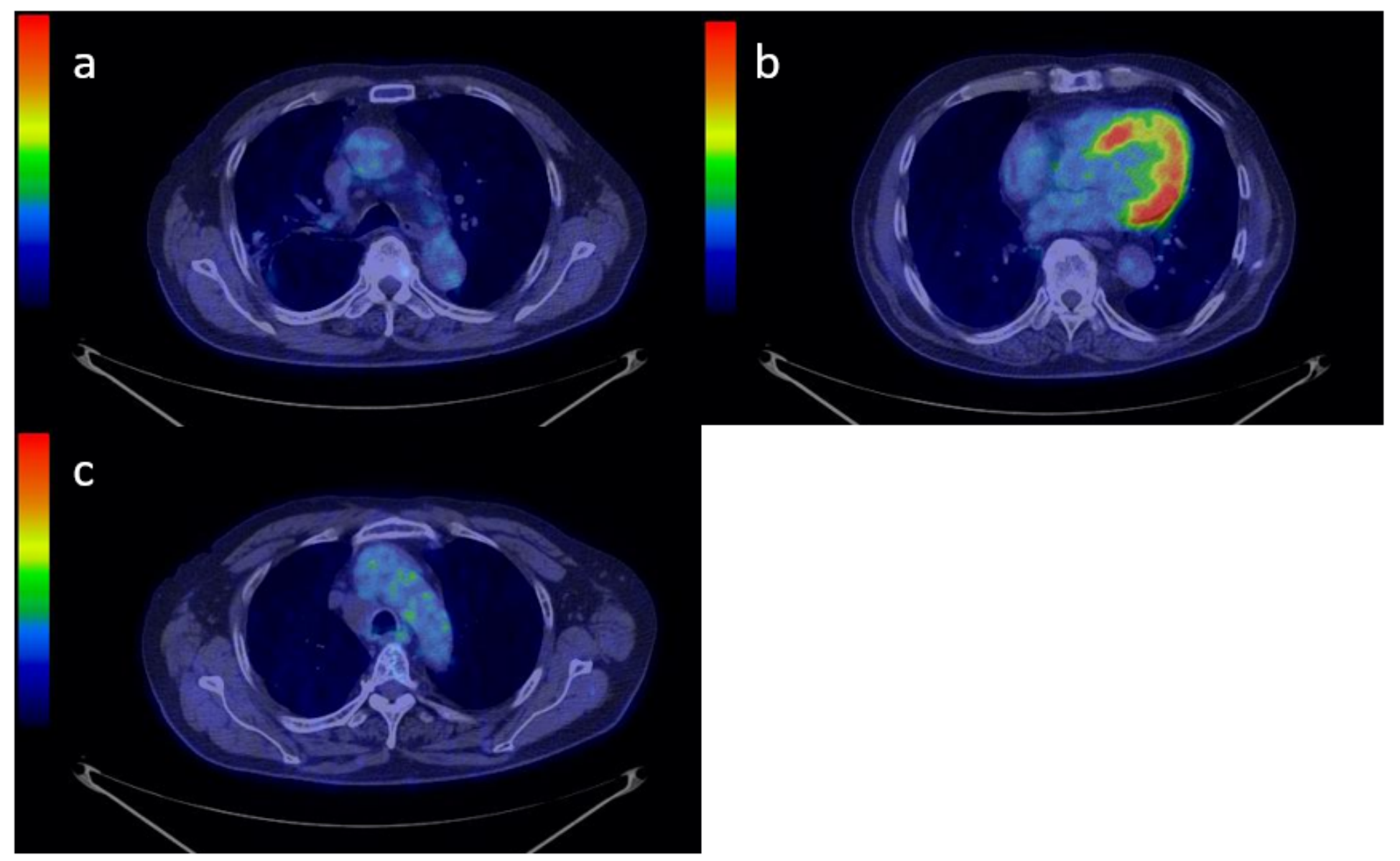

\section{Figure 3}

FDG-PET images showing weak accumulation of FDG in the primary tumor (a) but no accumulation on the left metastatic tumor (b) or mediastinal lymph nodes (c), even though the latter are still enlarged. 


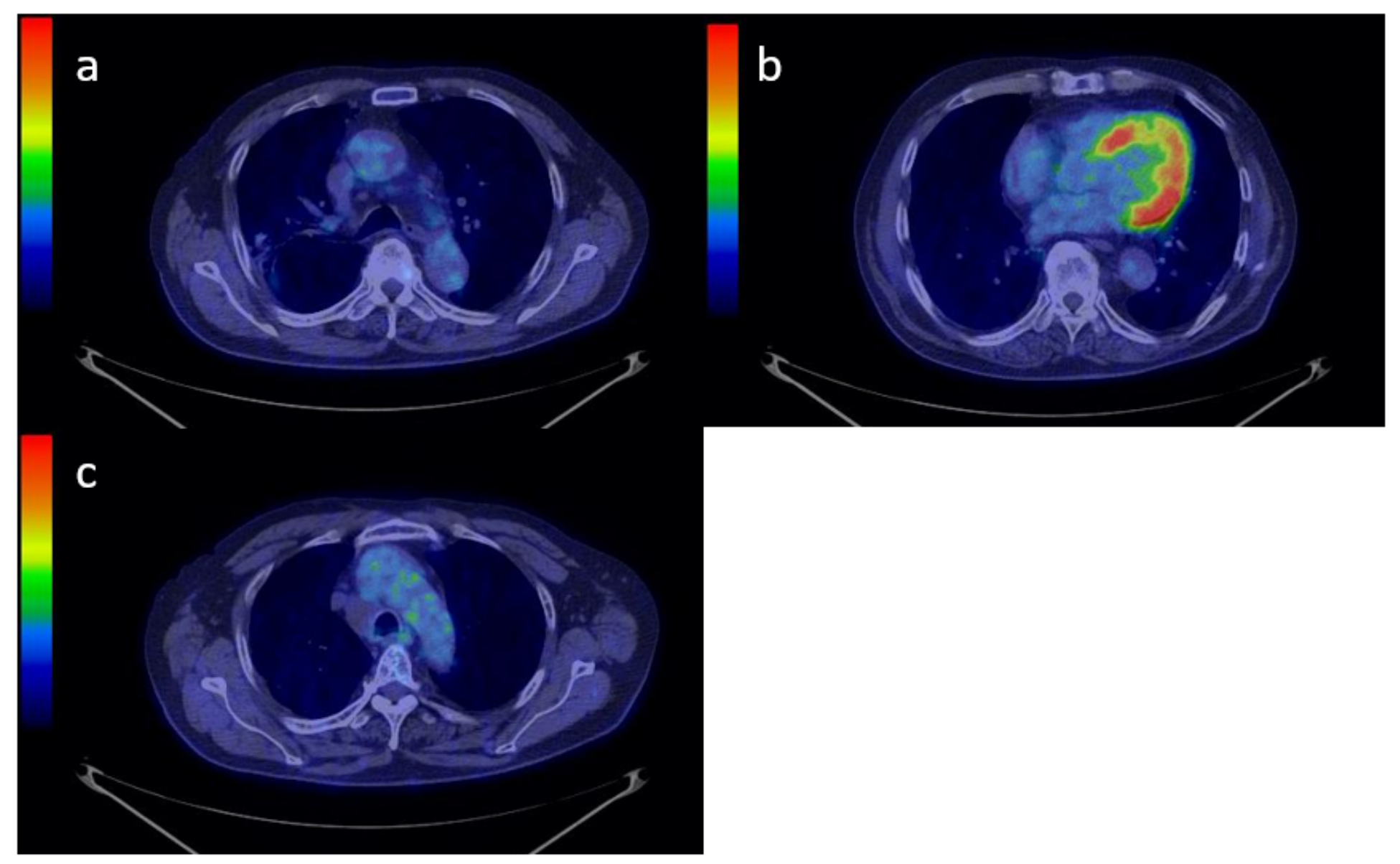

\section{Figure 3}

FDG-PET images showing weak accumulation of FDG in the primary tumor (a) but no accumulation on the left metastatic tumor (b) or mediastinal lymph nodes (c), even though the latter are still enlarged. 


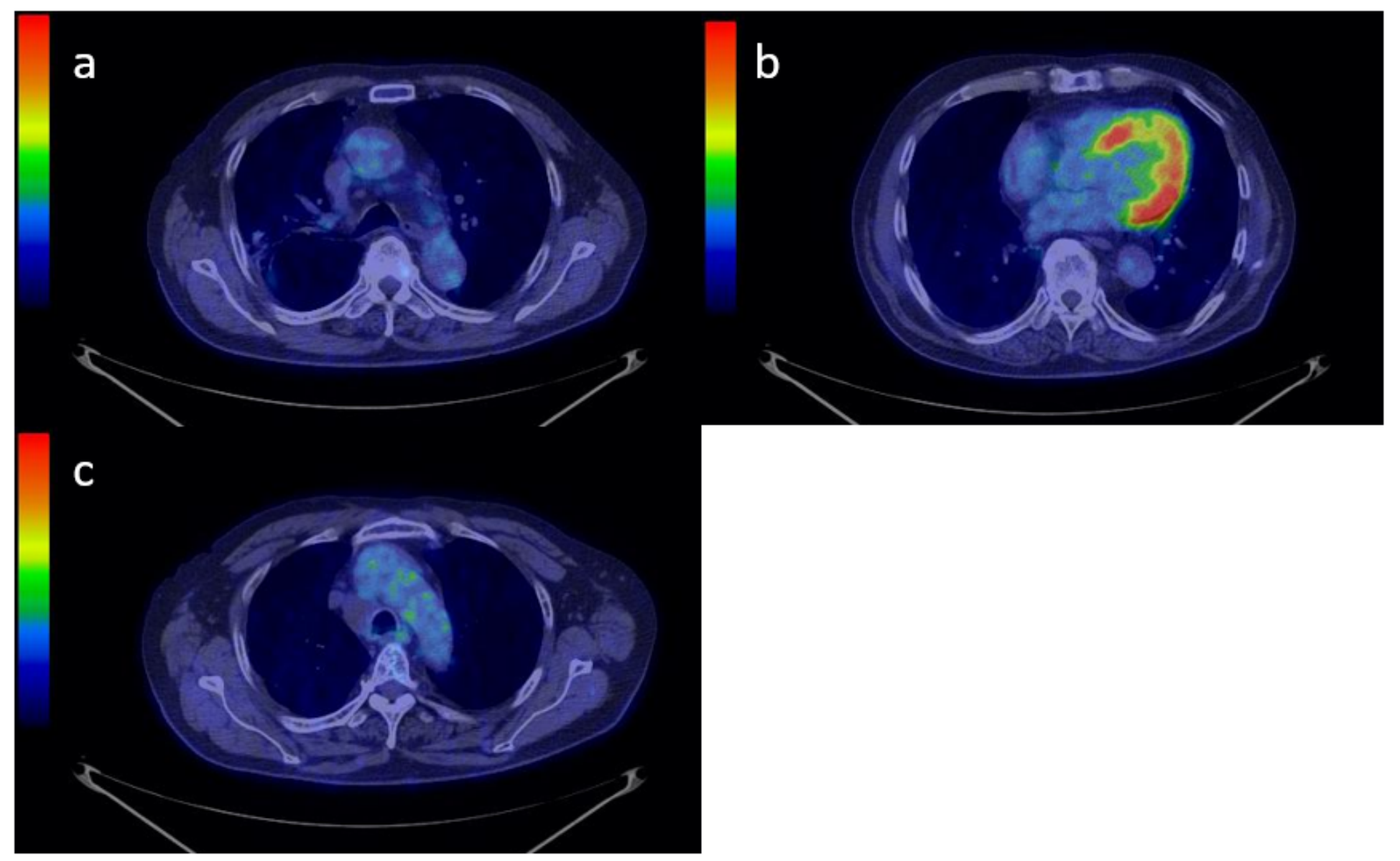

\section{Figure 3}

FDG-PET images showing weak accumulation of FDG in the primary tumor (a) but no accumulation on the left metastatic tumor (b) or mediastinal lymph nodes (c), even though the latter are still enlarged. 


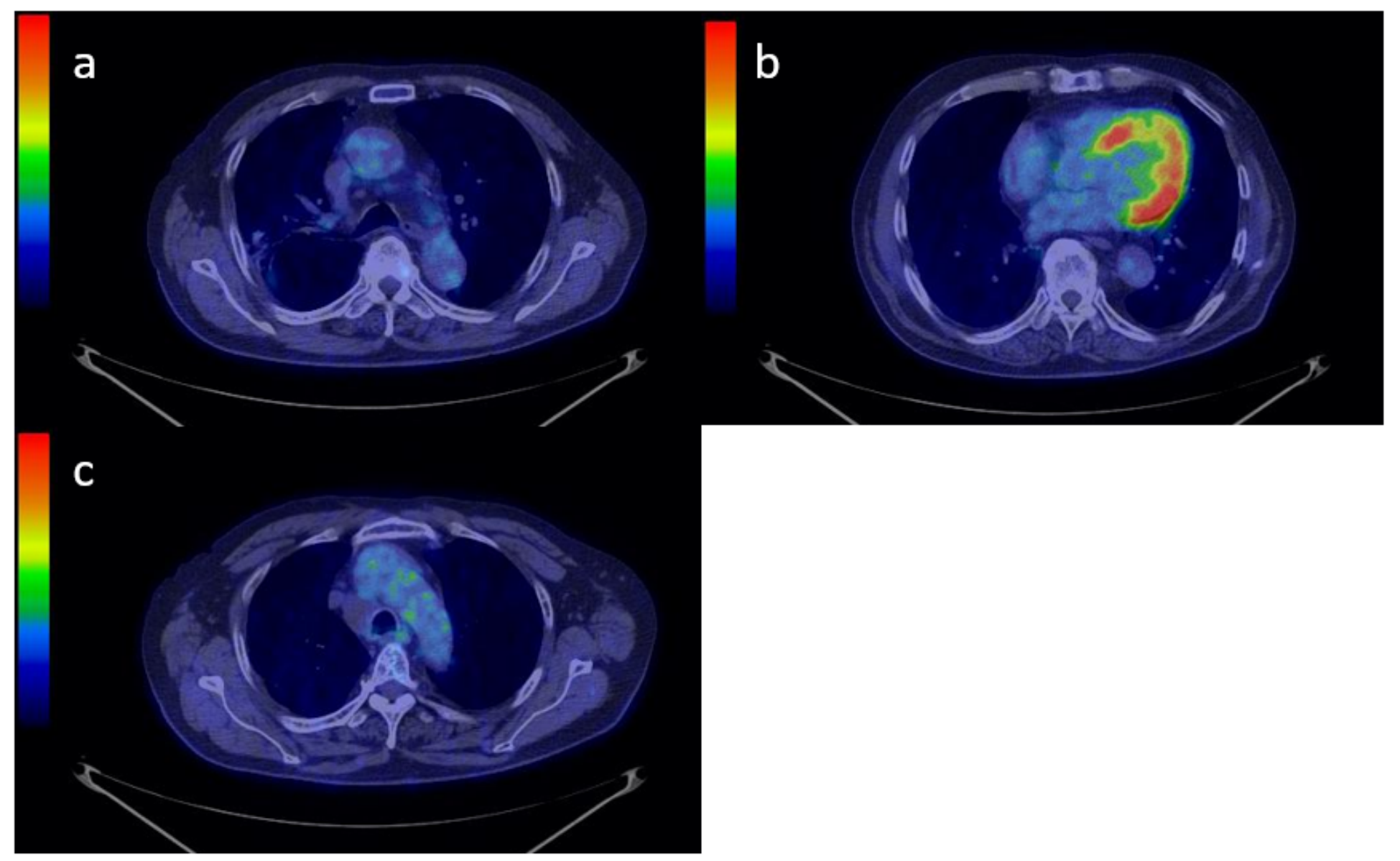

\section{Figure 3}

FDG-PET images showing weak accumulation of FDG in the primary tumor (a) but no accumulation on the left metastatic tumor (b) or mediastinal lymph nodes (c), even though the latter are still enlarged. 


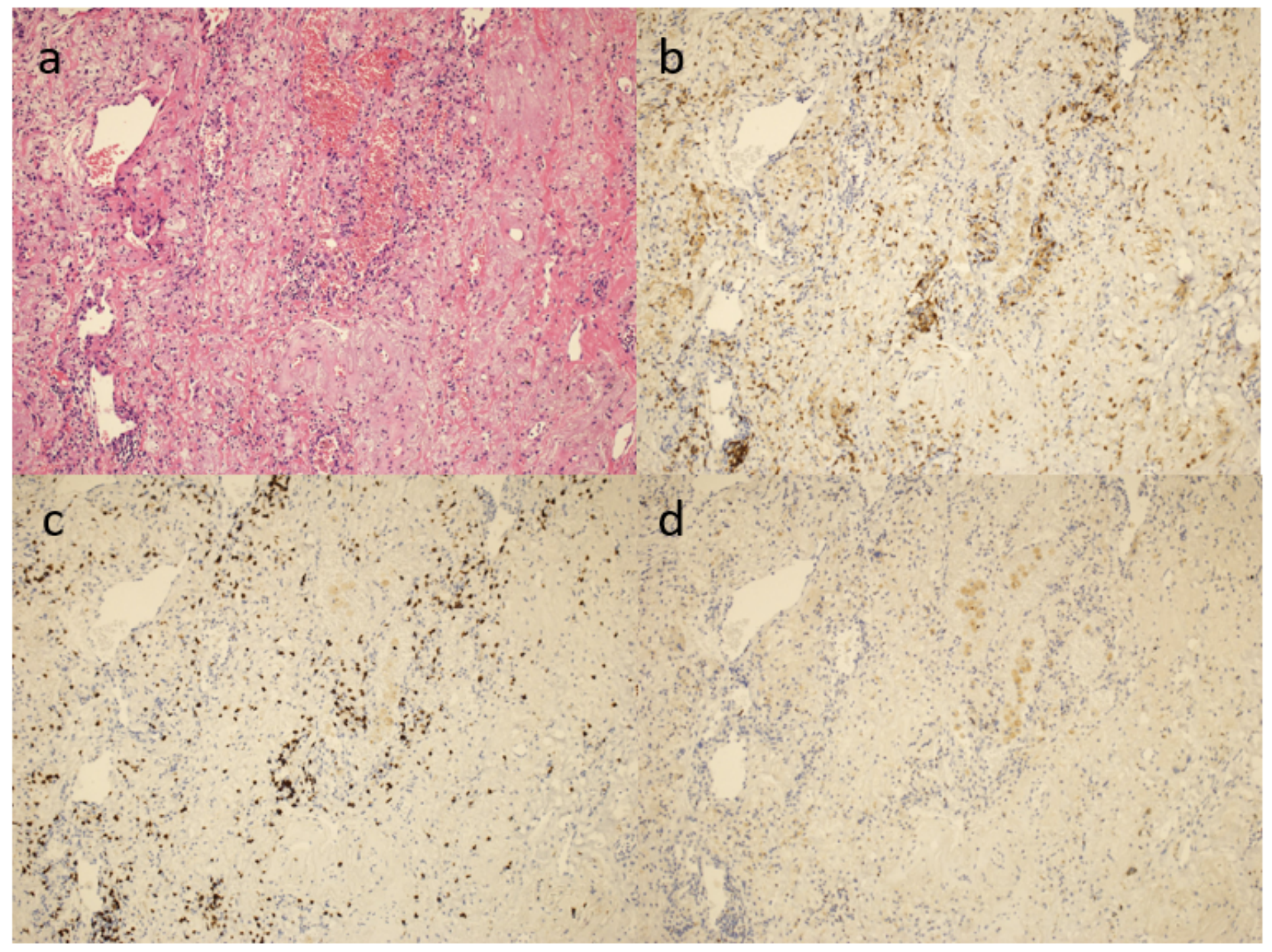

\section{Figure 4}

Photomicrographs of operative specimen showing that cancer tissue has been replaced by scar tissue $(\mathrm{H}$. E. $\times 100$ ) (a) and that CD4 positive T cells are predominant (anti-CD4 antibody $\times 100)(b)$ rather than CD8 positive T cells (anti-CD8 antibody $\times 100)($ c). Granzyme B is weakly positive (anti-granzyme antibody $\times 100)(d)$. 


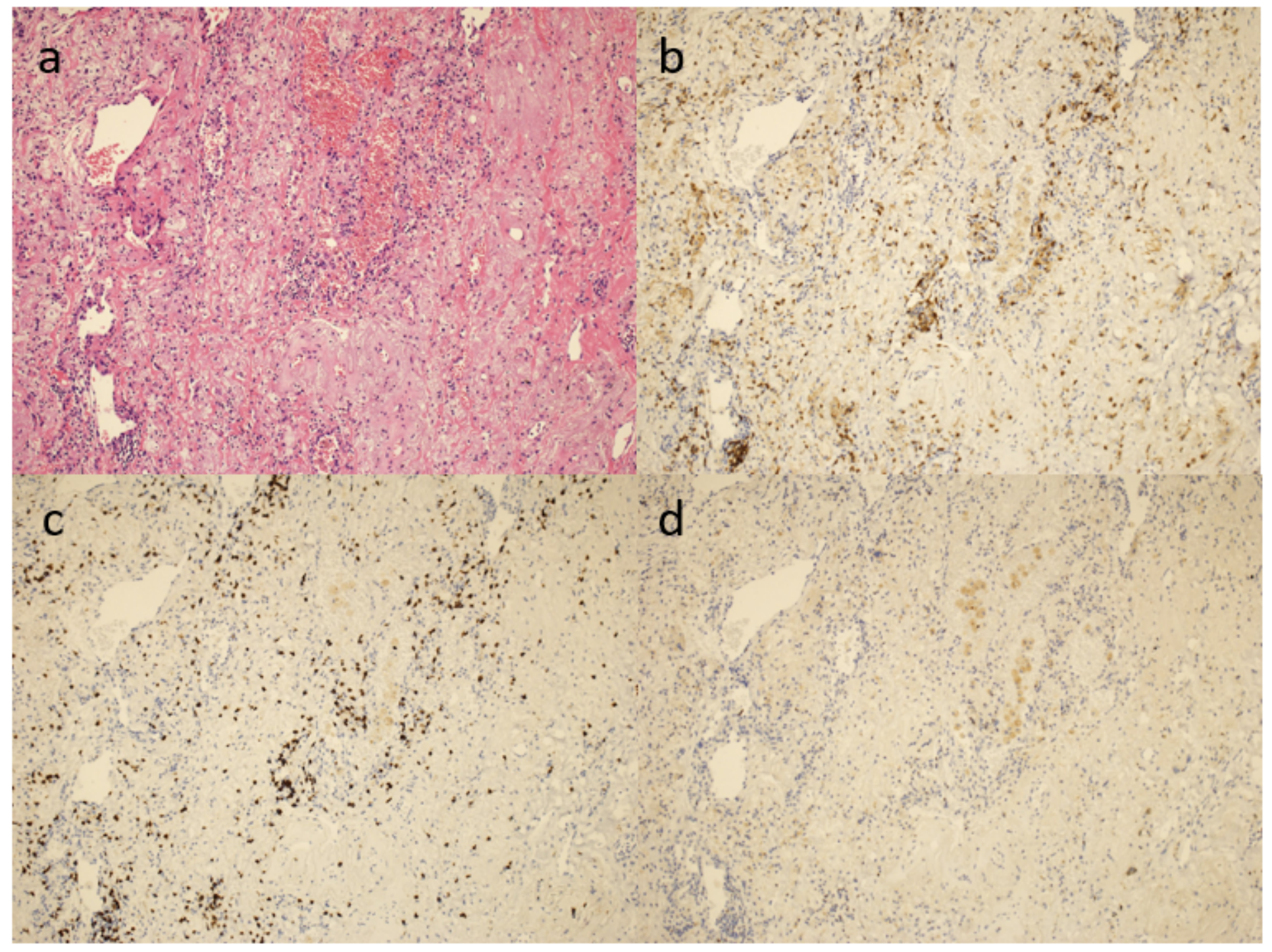

\section{Figure 4}

Photomicrographs of operative specimen showing that cancer tissue has been replaced by scar tissue $(\mathrm{H}$. E. $\times 100$ ) (a) and that CD4 positive T cells are predominant (anti-CD4 antibody $\times 100)(b)$ rather than CD8 positive T cells (anti-CD8 antibody $\times 100)($ c). Granzyme B is weakly positive (anti-granzyme antibody $\times 100)(d)$. 


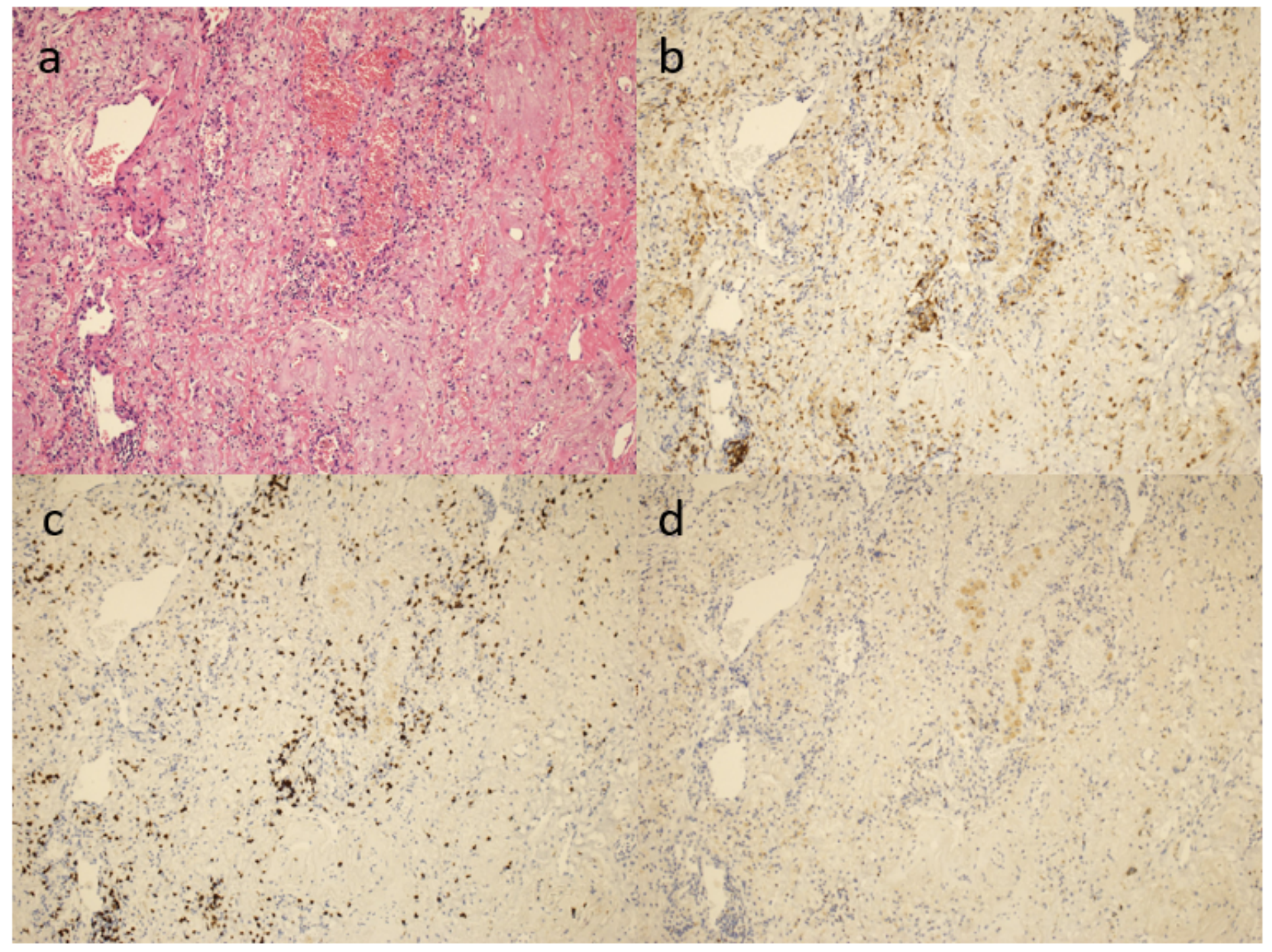

\section{Figure 4}

Photomicrographs of operative specimen showing that cancer tissue has been replaced by scar tissue $(\mathrm{H}$. E. $\times 100$ ) (a) and that CD4 positive T cells are predominant (anti-CD4 antibody $\times 100)(b)$ rather than CD8 positive T cells (anti-CD8 antibody $\times 100)($ c). Granzyme B is weakly positive (anti-granzyme antibody $\times 100)(d)$. 


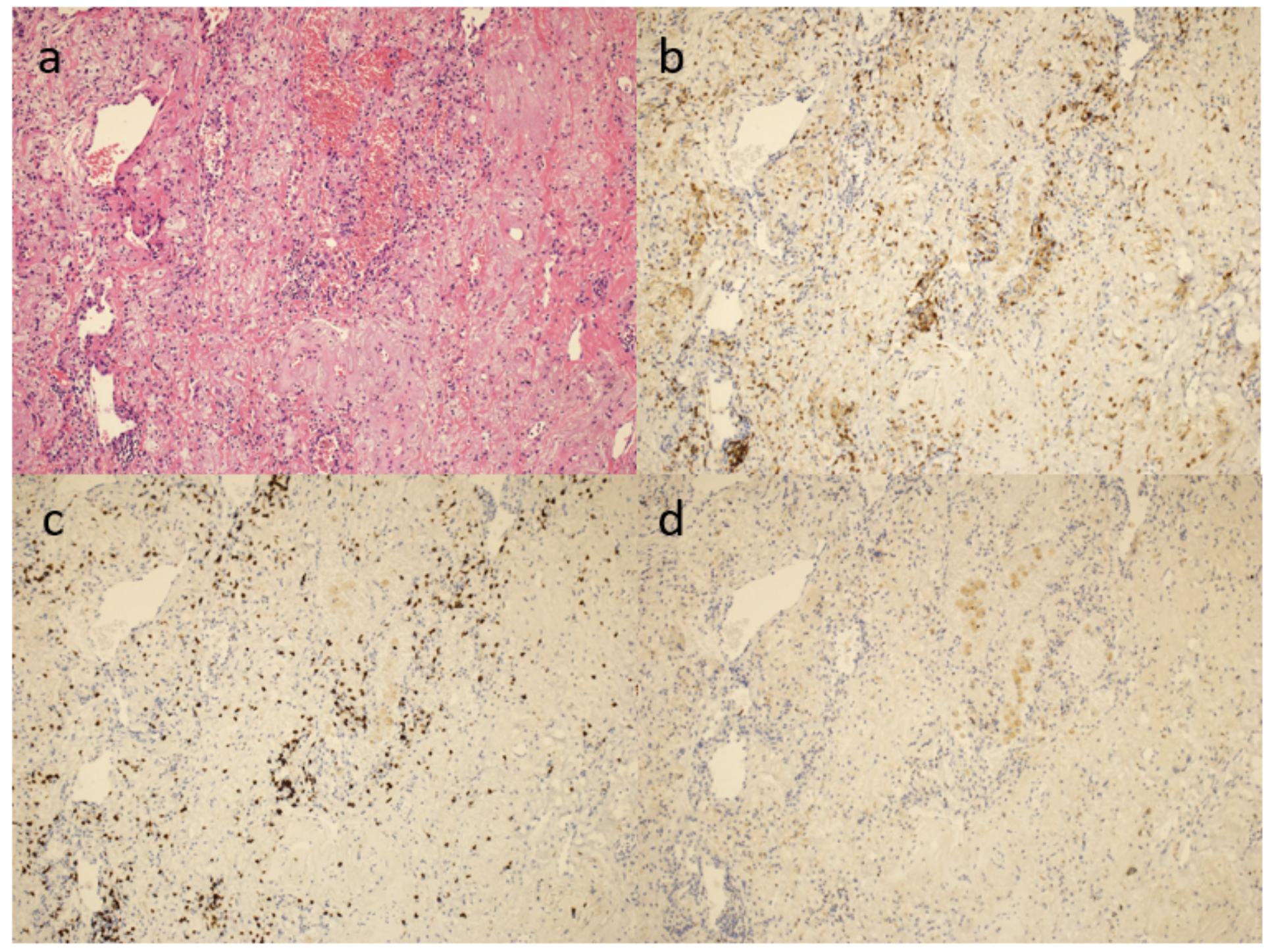

\section{Figure 4}

Photomicrographs of operative specimen showing that cancer tissue has been replaced by scar tissue $(\mathrm{H}$. E. $\times 100$ ) (a) and that CD4 positive T cells are predominant (anti-CD4 antibody $\times 100)(b)$ rather than CD8 positive T cells (anti-CD8 antibody $\times 100)($ c). Granzyme B is weakly positive (anti-granzyme antibody $\times 100)(d)$. 


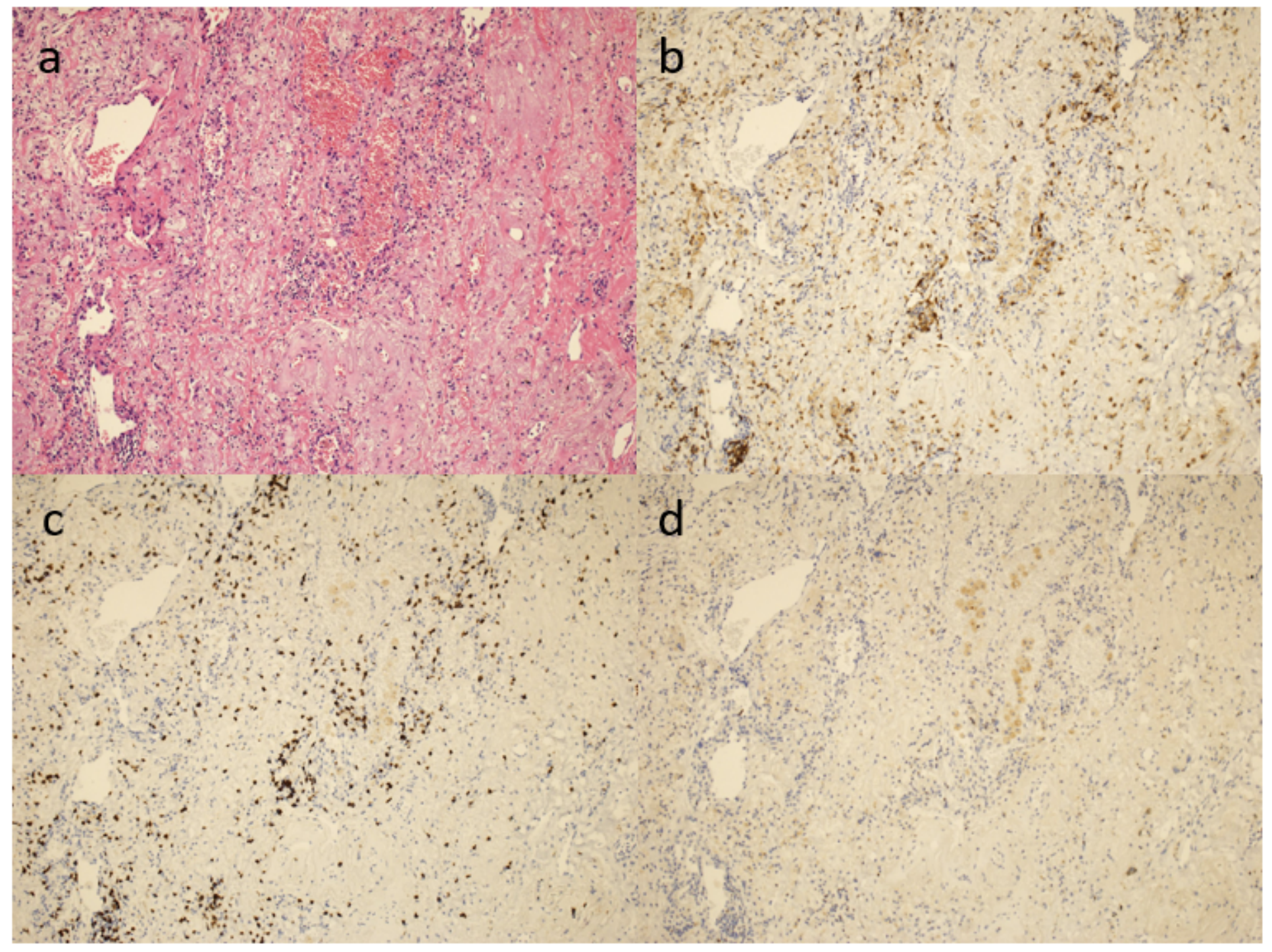

\section{Figure 4}

Photomicrographs of operative specimen showing that cancer tissue has been replaced by scar tissue $(\mathrm{H}$. E. $\times 100$ ) (a) and that CD4 positive T cells are predominant (anti-CD4 antibody $\times 100)(b)$ rather than CD8 positive T cells (anti-CD8 antibody $\times 100)($ c). Granzyme B is weakly positive (anti-granzyme antibody $\times 100)(d)$. 


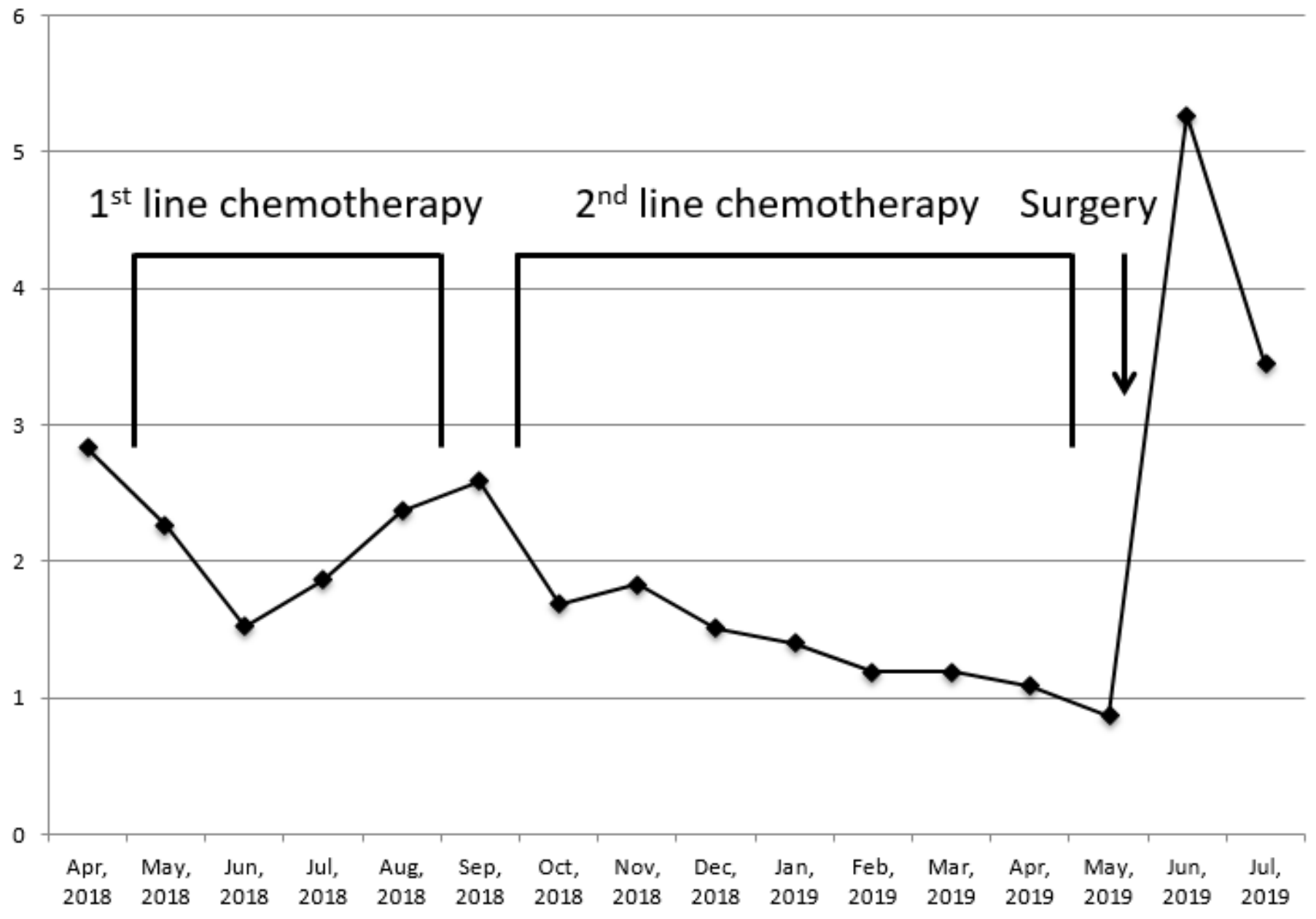

Figure 5

Changes of neutrophil-to-lymphocyte ratio (NLR). NLR was lower during immunotherapy compared with those before immunotherapy and after surgery. 


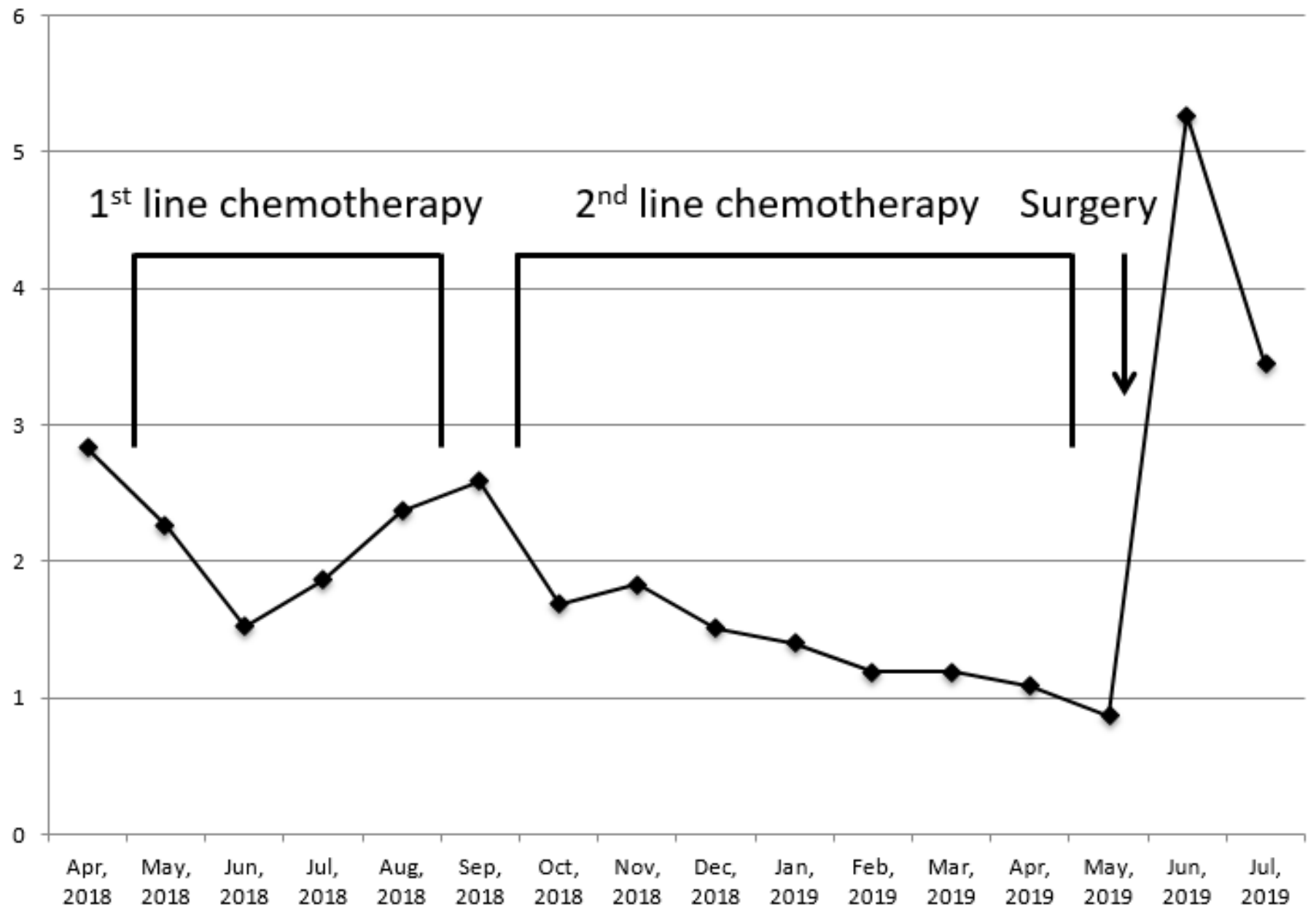

Figure 5

Changes of neutrophil-to-lymphocyte ratio (NLR). NLR was lower during immunotherapy compared with those before immunotherapy and after surgery. 


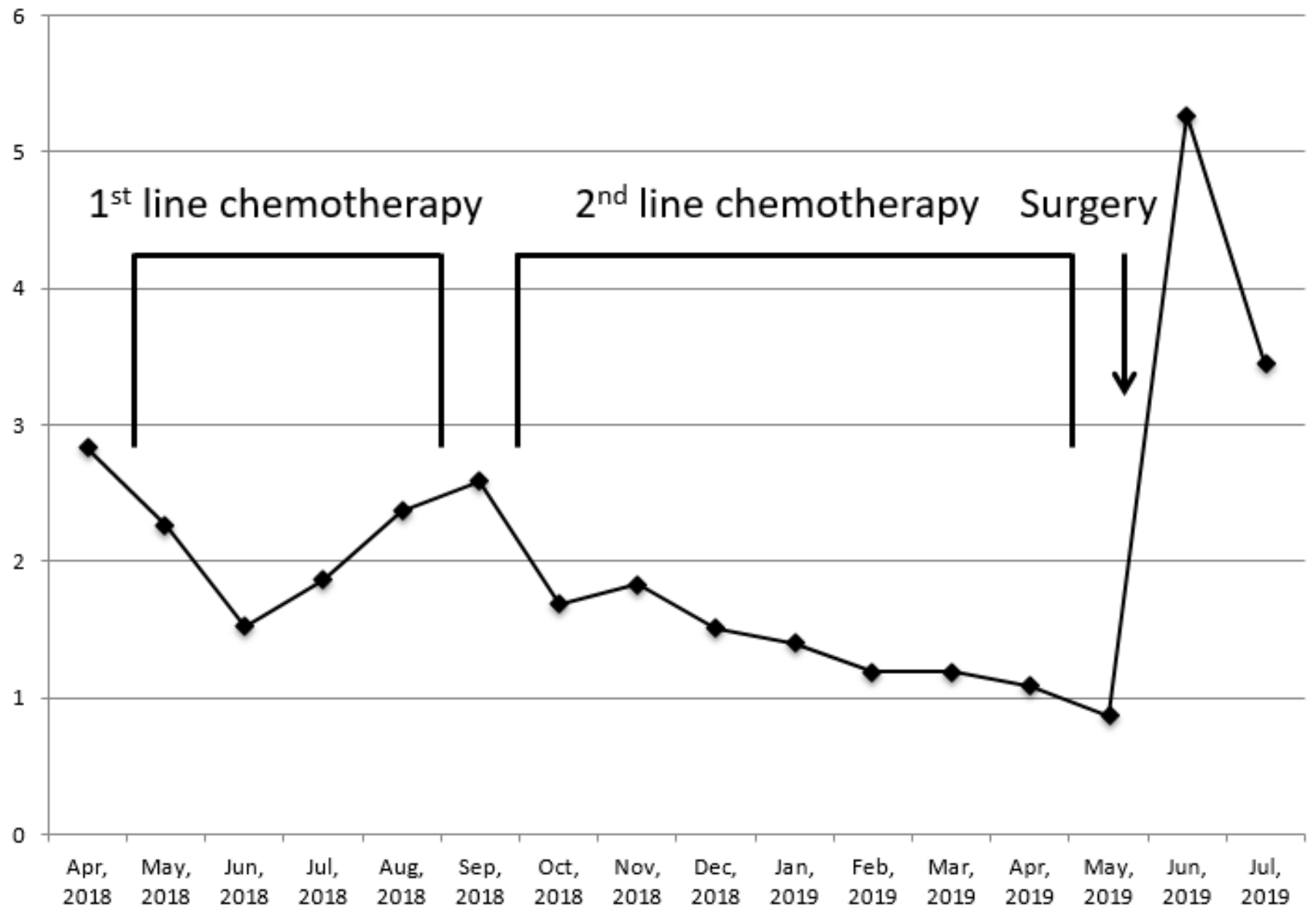

Figure 5

Changes of neutrophil-to-lymphocyte ratio (NLR). NLR was lower during immunotherapy compared with those before immunotherapy and after surgery. 


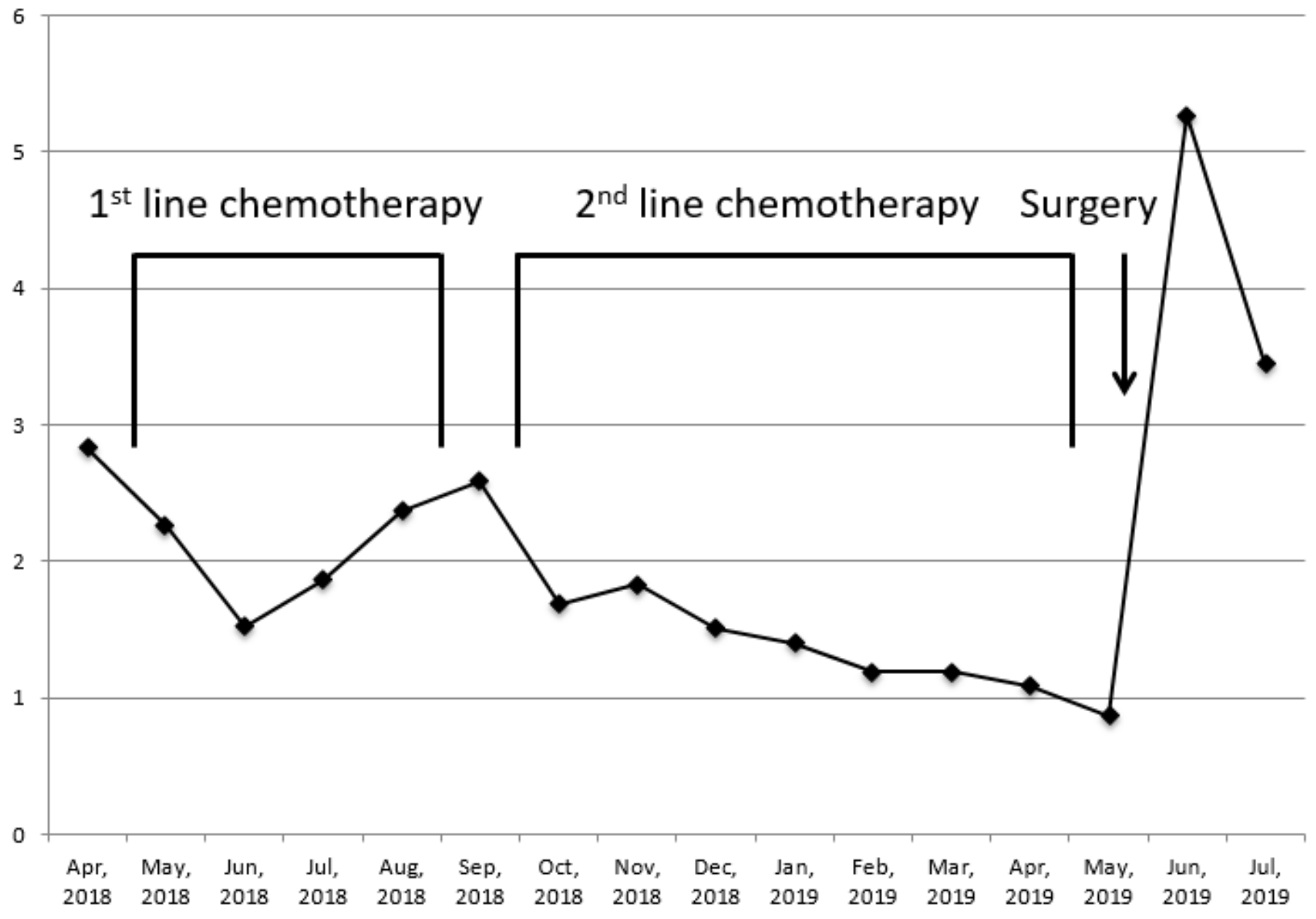

Figure 5

Changes of neutrophil-to-lymphocyte ratio (NLR). NLR was lower during immunotherapy compared with those before immunotherapy and after surgery. 


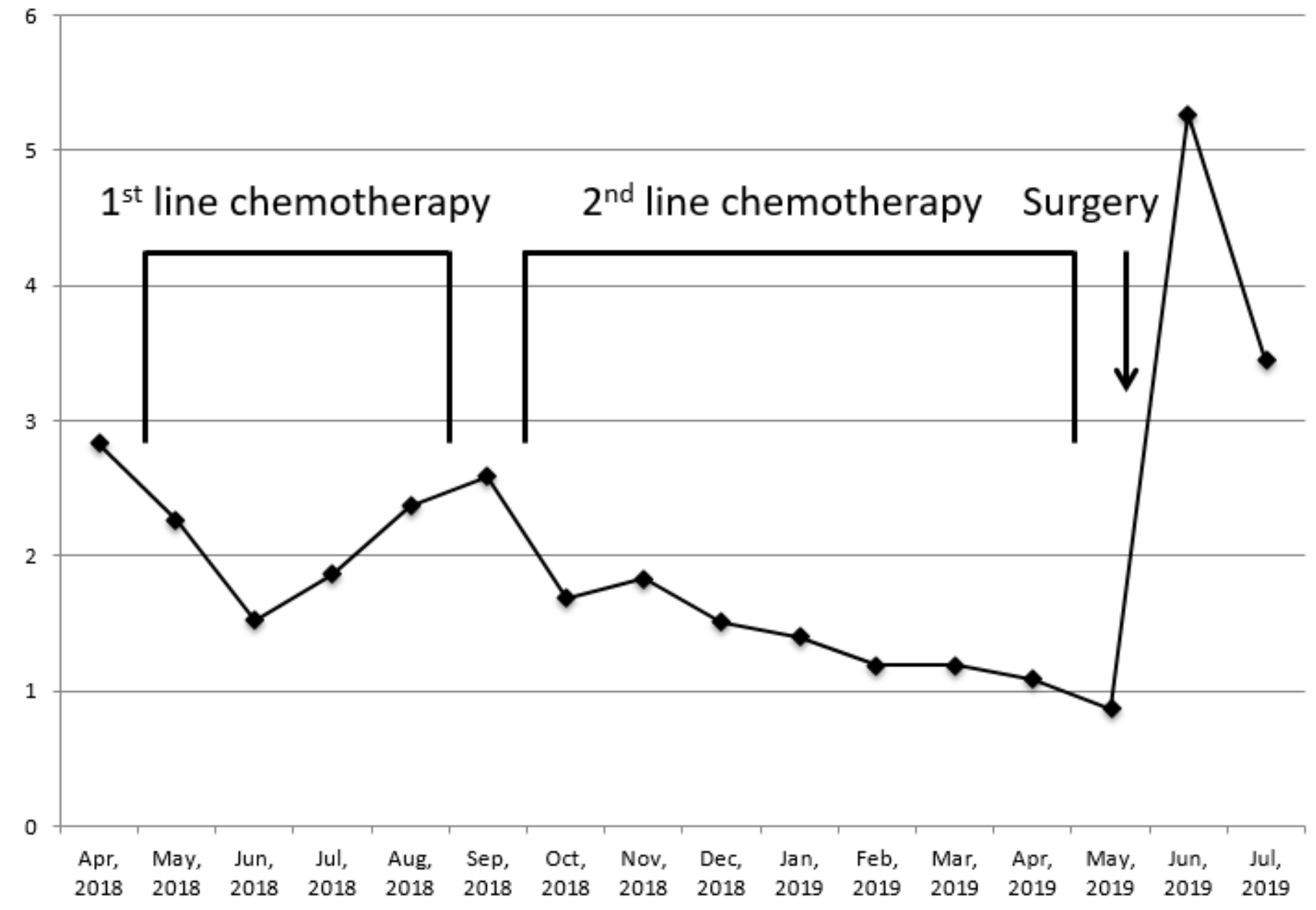

Figure 5

Changes of neutrophil-to-lymphocyte ratio (NLR). NLR was lower during immunotherapy compared with those before immunotherapy and after surgery.

\section{Supplementary Files}

This is a list of supplementary files associated with this preprint. Click to download.

- CRafterPembrolizumabTb.xlsx 